\title{
BMJ Open Initiatives for improving delayed discharge from a hospital setting: a scoping review
}

\author{
Lauren Cadel (D) , ${ }^{1,2}$ Sara J T Guilcher (D) ,2,3,4,5 Kristina Marie Kokorelias, ${ }^{3}$ \\ Jason Sutherland, ${ }^{6}$ Jon Glasby, ${ }^{7}$ Tara Kiran, ${ }^{4,5,8,9}$ Kerry Kuluski ${ }^{1,4}$
}

To cite: Cadel L, Guilcher SJT, Kokorelias KM, et al. Initiatives for improving delayed discharge from a hospital setting: a scoping review. BMJ Open 2021;11:e044291. doi:10.1136/ bmjopen-2020-044291

- Prepublication history and additional material for this paper is available online. To view these files, please visit the journal online (http://dx.doi.org/10. 1136/bmjopen-2020-044291)

Received 31 August 2020 Revised 18 January 2021 Accepted 25 January 2021
Check for updates

(C) Author(s) (or their employer(s)) 2021. Re-use permitted under CC BY-NC. No commercial re-use. See rights and permissions. Published by BMJ.

For numbered affiliations see end of article.

Correspondence to

Lauren Cadel;

lauren.cadel@thp.ca

\section{ABSTRACT}

Objective The overarching objective of the scoping review was to examine peer reviewed and grey literature for best practices that have been developed, implemented and/ or evaluated for delayed discharge involving a hospital setting. Two specific objectives were to review what the delayed discharge initiatives entailed and identify gaps in the literature in order to inform future work.

Design Scoping review.

Methods Electronic databases and websites of government and healthcare organisations were searched for eligible articles. Articles were required to include an initiative that focused on delayed discharge, involve a hospital setting and be published between 1 January 2004 and 16 August 2019. Data were extracted using Microsoft Excel. Following extraction, a policy framework by Doern and Phidd was adapted to organise the included initiatives into categories: (1) information sharing; (2) tools and guidelines; (3) practice changes; (4) infrastructure and finance and (5) other.

Results Sixty-six articles were included in this review. The majority of initiatives were categorised as practice change $(n=36)$, followed by information sharing $(n=19)$ and tools and guidelines $(n=19)$. Numerous initiatives incorporated multiple categories. The majority of initiatives were implemented by multidisciplinary teams and resulted in improved outcomes such as reduced length of stay and discharge delays. However, the experiences of patients and families were rarely reported. Included initiatives also lacked important contextual information, which is essential for replicating best practices and scaling up.

Conclusions This scoping review identified a number of initiatives that have been implemented to target delayed discharges. While the majority of initiatives resulted in positive outcomes, delayed discharges remain an international problem. There are significant gaps and limitations in evidence and thus, future work is warranted to develop solutions that have a sustainable impact.

\section{INTRODUCTION}

A delayed hospital discharge (known as alternate level of care (ALC) in Canada and delayed transfer of care in the UK) occurs when a patient is medically approved to be discharged, but remains in hospital for nonmedical reasons (eg, waiting for a long-term care bed to become available or to transfer

\section{Strengths and limitations of this study}

To our knowledge, this is the first scoping review to identify best practices for delayed discharges involving a hospital setting.

- The Preferred Reporting Items for Systematic Reviews and Meta-Analyses extension for Scoping Reviews Checklist was followed.

- A comprehensive search of peer reviewed and grey literature was conducted.

- A critical appraisal of the interventions was not performed.

home with services). ${ }^{1}$ While waiting for their next destination, patients' level of care and activation often decrease or stop entirely. Delayed discharge can result in hospital patient flow issues (eg, emergency service backlogs, cancelled surgeries, delays in medically necessary care), ${ }^{2}$ increased healthcare costs, ${ }^{3}$ an increased risk of functional decline, ${ }^{4}{ }^{5}$ falls, ${ }^{6}$ hospital-related adverse events (eg, medication error, exposure to infectious disease), ${ }^{67}$ mortality, ${ }^{8}$ as well as poor patient and family experiences. ${ }^{9}$

Patients who experienced a delayed discharge in previous studies exhibited the following characteristics: female, ${ }^{10}$ older, ${ }^{10}{ }^{11}$ physically or cognitively impaired. ${ }^{42-15}$ Patients have also shown to exhibit aggressive behaviours, ${ }^{16}$ use assistive devices ${ }^{17}$ and have psychiatric conditions, ${ }^{10}$ neurological disorders ${ }^{15}$ and/or multimorbidity. ${ }^{17}$ In addition to these patient-level factors, there are a number of system-level factors that contribute to delayed discharges, including long wait lists for long-term care facilities, ${ }^{5}{ }^{17-19}$ rehabilitation or other postacute care (eg, home care), ${ }^{11} 12$ 20-23 the lack of culturally and religiously diverse long-term care facilities, ${ }^{15}$ limited or absent hospital services on weekends ${ }^{24}$ and organisational delays (eg, administrative delays, delayed assessments). ${ }^{24} 25$ There are also 
different pressures and priorities across sectors, with little incentive to work together as a system. For example, while hospitals may be focused on efficiency and throughput, community-based organisations may be focused on empowerment, longer-term quality of life outcomes and working at a pace that works for patients and families. The funding structure of hospitals and healthcare systems can also have an impact on overall patient flow, including discharge delays. Although there is wide variation in funding structures within and across countries, there is potential for funding to either incentivise or disincentivise timely hospital discharges. ${ }^{26-30}$

The combination of patient-level and system-level factors contributing to delayed discharges can also have a large financial impact on patients, families, healthcare providers and the healthcare system. ${ }^{3}$ A recent systematic review reported that delayed discharges cost approximately £200-565 (\$C320-\$C900) per patient, per day. ${ }^{3}$ Further, it was estimated that the National Health Service (NHS) (England) spends $£ 820$ million ( $\$ \mathrm{C} 1.3$ billion) every year on patients who have a discharge delay. ${ }^{31}$ Similarly, a recent report from Canada stated that three hospitals located in Ottawa, Ontario, spend approximately \$C250 000 per day (combined) on patients occupying beds at a level of care they no longer require. ${ }^{32}$ In addition to large costs for hospitals and healthcare systems, delayed hospital discharges can result in out-of-pocket costs for patients and families. ${ }^{33}$ Increased out-of-pocket costs, in addition to the other uncertainties associated with a delay, can heighten stress for patients and families, contribute to poor experiences and compromise quality of life. ${ }^{9}$

Overall, delayed hospital discharges are problematic internationally, highlighting a need to identify best practices and current initiatives that are concentrating on solutions to this complex problem. To date, the majority of published literature on delayed discharge has focused on risk factors and characteristics of patients who experience delayed discharge. There has been a limited focus on initiatives that address the delayed discharge problem. Therefore, the purpose of this scoping review was to examine peer reviewed and grey literature (literature published through non-traditional means) for initiatives that have been developed and/or evaluated for delayed discharge from a hospital setting, with the goal of identifying best practices for reducing delayed discharge. A scoping review methodology was appropriate for addressing this goal, in order to identify the types of available evidence on this topic, examine key characteristics relating to initiatives for delayed discharge and to identity knowledge gaps. ${ }^{34}$

\section{METHODS}

This review followed the scoping review methodology outlined by Levac et $a l,{ }^{35}$ as well as the recently developed Preferred Reporting Items for Systematic Reviews and Meta-Analyses extension for Scoping Reviews (see online supplemental table 1). ${ }^{36}$ A protocol for this scoping review was developed in consultation with a librarian at the University of Toronto, with continuous input from members of the research team.

\section{Stage 1: identifying the research question}

The research question developed to lead this scoping review was: what is known in the literature about initiatives (eg, strategies, programmes, interventions) that have been developed, implemented and/or evaluated for delayed discharge involving a hospital setting? The two main aims were: (1) to review what delayed discharge initiatives entail (eg, characteristics, outcomes) and (2) to identify gaps in the literature in order to inform future studies.

\section{Stage 2: identifying relevant articles}

The search strategy was developed with a librarian at the University of Toronto and through consultations with an advisory group and collaborators who have experience in clinical practice or administration (see online supplemental table 2 for Medline search strategy). Each search strategy was adapted for the specific database using appropriate command line syntax and indexing. The following are examples of keywords searched using Boolean operators, proximity operators, wild cards and truncations: ALC, delayed discharge, delayed transfer, bed blocking, strategy, model, intervention, programme, policy.

Electronic databases were searched for relevant articles. The following electronic databases were searched on 16 August 2019: MEDLINE (Ovid Interface), EMBASE (Ovid Interface), AMED (Ovid Interface), Cumulative Index to Nursing and Allied Health Literature (EBSCO Interface) and Cochrane Library. Grey literature was searched on the following databases and repositories: OpenGrey, Health Services Research Projects in Progress, UpToDate, Community Research and Development Information Services and TSpace, as well as on numerous national and international healthcare and government websites. We also reached out to key stakeholders, including members of our advisory group, to send us relevant reports and presentations.

\section{Stage 3: study selection}

For inclusion, articles (peer-reviewed and grey literature) were required to meet the following criteria: (1) focused on delayed discharge, (2) included an initiative to address delayed discharge, (3) involved a hospital setting, (4) published between 1 January 2004 and 16 August 2019 and (5) peer-reviewed or grey literature. We focused our inclusion on initiatives involving a hospital setting because this is where the problem of delayed discharges surfaces. Articles were excluded if they met any one of the following criteria: (1) focused on changing the threshold/timing of discharge (early discharge), (2) books, book chapters, opinion pieces or editorials, (3) grey literature that did not sufficiently describe the initiative implemented (eg, implementation process, location, population, impact); 


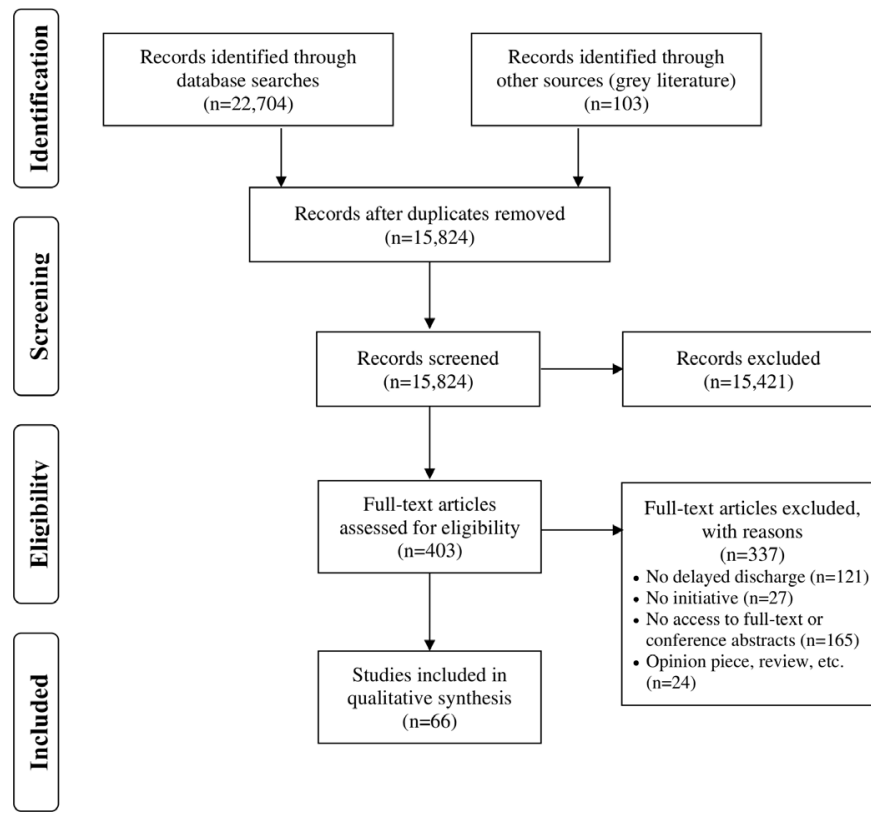

Figure 1 PRISMA flow diagram of included articles. PRISMA, Preferred Reporting Items for Systematic Reviews and Meta-Analyses.

(4) protocols, trial papers or chart reviews or (5) conference abstracts or articles without an accessible full text. Articles were excluded for criteria one (changing the threshold/timing of discharge) because the rationale for having an earlier discharge was often focused on other factors such as cost-savings by reducing length of stay, rather than specifically addressing a delayed discharge. Articles were excluded if they met criteria two (books, book chapters, opinion pieces or editorials) to eliminate articles with potential personal biases and summaries of peer-reviewed literature. Grey literature that did not provide sufficient details on the initiative (such as lacking a description of the components of the initiative) were excluded. Articles published more than 15 years ago, before 1 January 2004, were excluded to ensure the initiatives included in this scoping review were relevant to more current health service practices.

Articles identified from the database searches were imported into EndNote X9, a reference management software, where they were deduplicated following Bramer's method. ${ }^{37}$ The initial database searches identified 22704 articles, which were reduced to 15824 following deduplication (figure 1). The titles and abstracts of the articles were reviewed on Covidence, a software platform for systematic and scoping reviews. ${ }^{38}$ The research team (LC, KK, SJTG, KMK and JK) independently screened the titles and abstracts of 40 articles to test their agreement. The reviewers had a good per cent agreement (85\%), so the remaining articles were divided among the team and screened by single reviewers (LC, KMK and JK). All disagreements were discussed in-person by the reviewers until a consensus was reached; minor revisions were made to the eligibility criteria to ensure clarity and consistency. Following title and abstract screening, articles were reviewed at the full-text level. Thirty full-text articles were independently screened by the research team (LC, KK, SJTG, KMK, JK and MA) to test their interrater agreement. The remaining full-text articles (peer-reviewed and grey literature) were double screened by four reviewers (LC, KMK, JK and MA).

\section{Stage 4: charting the data}

The data were charted by two reviewers (LC and KMK) using a data extraction form in Microsoft Excel. The form was developed and tested by the research team in a series of team meetings prior to the extraction of all data. We conducted spot checking of extracted data from $15 \%$ of the included articles to ensure completeness and accuracy of the extracted data. Any questions that arose during the charting process were discussed by the team. Charted data contained the following information: general information, study characteristics, population characteristics, initiative characteristics, characteristics of delayed discharge, study outcomes and conclusions.

\section{Stage 5: collating, summarising and reporting results}

Microsoft Excel was used to conduct a descriptive quantitative analysis of the included articles, as well as facilitate qualitative thematic analysis. The thematic analysis of the charted data was an inductive and iterative process, in which the team (LC, SJTG, KMK and KK) met in-person to discuss high level concepts and identified common themes across the included articles. When reviewing the extracted data, we found that the strategies appeared to cluster into core categories, which aligned with a conceptual framework developed by Doern and Phidd. ${ }^{39}$ This framework classifies policy instruments/tools along a continuum (from those that are least coercive like information sharing to those that are more coercive like public ownership or, in our case, new infrastructure). We deductively applied Doern and Phidd's categories to classify our findings, with some minor adaptations. The five adapted categories were not mutually exclusive and included: (1) information sharing (live information sharing and documented recommendations); (2) tools and guidelines; (3) practice changes; (4) infrastructure and finance and (5) other (see table 1 for category descriptions and examples). The categories assisted with the organisation and presentation of the data.

\section{Stage 6: consultation}

The research team presented findings of the scoping review to key stakeholders (eg, hospital staff, patient and caregiver partners) through the planning process and analysis of results. These meetings were used to inform search terms, gather relevant documents, obtain feedback on the categorisation/organisation of initiatives, as well as identify knowledge gaps in order to develop targeted and actionable recommendations for future practice, policy and research. 
Table 1 Categories, descriptions and examples of initiative categorisation

\begin{tabular}{|c|c|c|}
\hline Category name & Description & Examples \\
\hline $\begin{array}{l}\text { Information Sharing } \\
\text { A-live sharing } \\
\text { B-recommended } \\
\text { initiatives - calls to action }\end{array}$ & $\begin{array}{l}\text { A-information sharing through in-person } \\
\text { or technology-based communication } \\
\text { (synchronous communication) } \\
\text { B-information sharing through documents } \\
\text { which share suggestions, recommendations or } \\
\text { for information purposes (motivation) }\end{array}$ & $\begin{array}{l}\text { A-rounding, team meetings, one-on-on } \\
\text { communication } \\
\text { B-examples: suggested strategies } \\
\text { (or 'calls to action') which ranged from } \\
\text { recommending investments in new long- } \\
\text { term care beds, increasing funding for } \\
\text { behavioural supports, audits and reports, } \\
\text { encouraging team building }\end{array}$ \\
\hline Tools and guidelines & $\begin{array}{l}\text { Tangible/concrete guides to inform practice } \\
\text { Implemented tool/guidance document that is } \\
\text { being used in the healthcare system }\end{array}$ & $\begin{array}{l}\text { Toolkits, guidelines, escalation processes, } \\
\text { frameworks }\end{array}$ \\
\hline Practice changes & A change in how care is delivered & $\begin{array}{l}\text { Nurse-led discharges, roles of providers } \\
\text { and/or composition of team are organised } \\
\text { differently }\end{array}$ \\
\hline Other initiatives & $\begin{array}{l}\text { Different initiative that does not fit into any of } \\
\text { the above categories }\end{array}$ & - Statistical models (predictive modelling) \\
\hline
\end{tabular}

\section{Patient and public involvement}

An advisory council (patient and caregiver partners), along with providers, managers and organisational leaders identified the lack of understanding about the state of evidence around best practices for delayed discharges, which informed the research question for this scoping review. The advisory council was involved with planning meetings where they provided feedback on the search terms and analysis. Results will be disseminated to the advisory council through presentations and a lay summary.

\section{RESULTS}

\section{Study characteristics}

The database search identified 15824 unique articles that were screened for eligibility; following title/abstract and full-text review, 66 articles were included in this scoping review, 49 articles from the database searches and 17 articles from the grey literature searches (figure 1). The majority of included articles were quantitative studies $(n=34)$, with a few qualitative $(n=5)$, mixed methods $(n=6)$ or other designs (policy analyses, reviews, case studies and presentations; $\mathrm{n}=21$ ). There was a large variety of study designs, with few randomised trials and prospective studies. Most initiatives were evaluated $(\mathrm{n}=42)$, with different types of evaluations such as process evaluations and outcome evaluations. The UK $(n=21)$, USA $(n=18)$ and Canada $(n=17)$ were the most common countries where studies were conducted. Based on the year of publication, there was a fairly even distribution of peer-reviewed articles across the years of inclusion (from 2004 to 2019); however, the majority of grey literature was published in the last 10 years. Table 2 describes the characteristics of included articles.
The initiatives most commonly targeted adults and older adults; however, there were some initiatives targeting the paediatric population. Specific characteristics of the study population (ie, age, sex, gender, ethnicity/race, income level, education, marital status, household composition, employment status, comorbidities) were not reported in the majority of articles. Most peer-reviewed articles $(n=31)$ defined a delayed discharge; however, there was a wide variety of definitions for these terms (see online supplemental table 3). The most common definition for delayed discharge was when a patient was identified as medically ready for discharge, but remained in hospital. Table 3 describes the initiative characteristics.

Based on Doern and Phidd's adapted framework, ${ }^{39}$ we categorised the included initiatives as: information sharing $(n=19)$; tools and guidelines $(n=19)$; practice changes $(n=36)$; infrastructure and finance $(n=10)$; or other $(n=3)$, which are described in detail below (see figure 2). Numerous articles used a combination of categories in their initiatives (eg, information sharing and practice change).

\section{Information sharing}

The information sharing category included initiatives that promoted communication, leadership from senior staff and information exchange within or across organisations. ${ }^{2}{ }^{40-55}$ The majority of information sharing initiatives included team meetings and huddles to facilitate communication through in-person interactions between staff, and less often between staff and patients/families. ${ }^{4041434446}$ Information sharing was promoted between multidisciplinary teams and patients to improve length of stay and continuity of care. For example, Adlington et al implemented Plan Do Study Act cycles during weekly quality improvement meetings, in which driver diagrams 


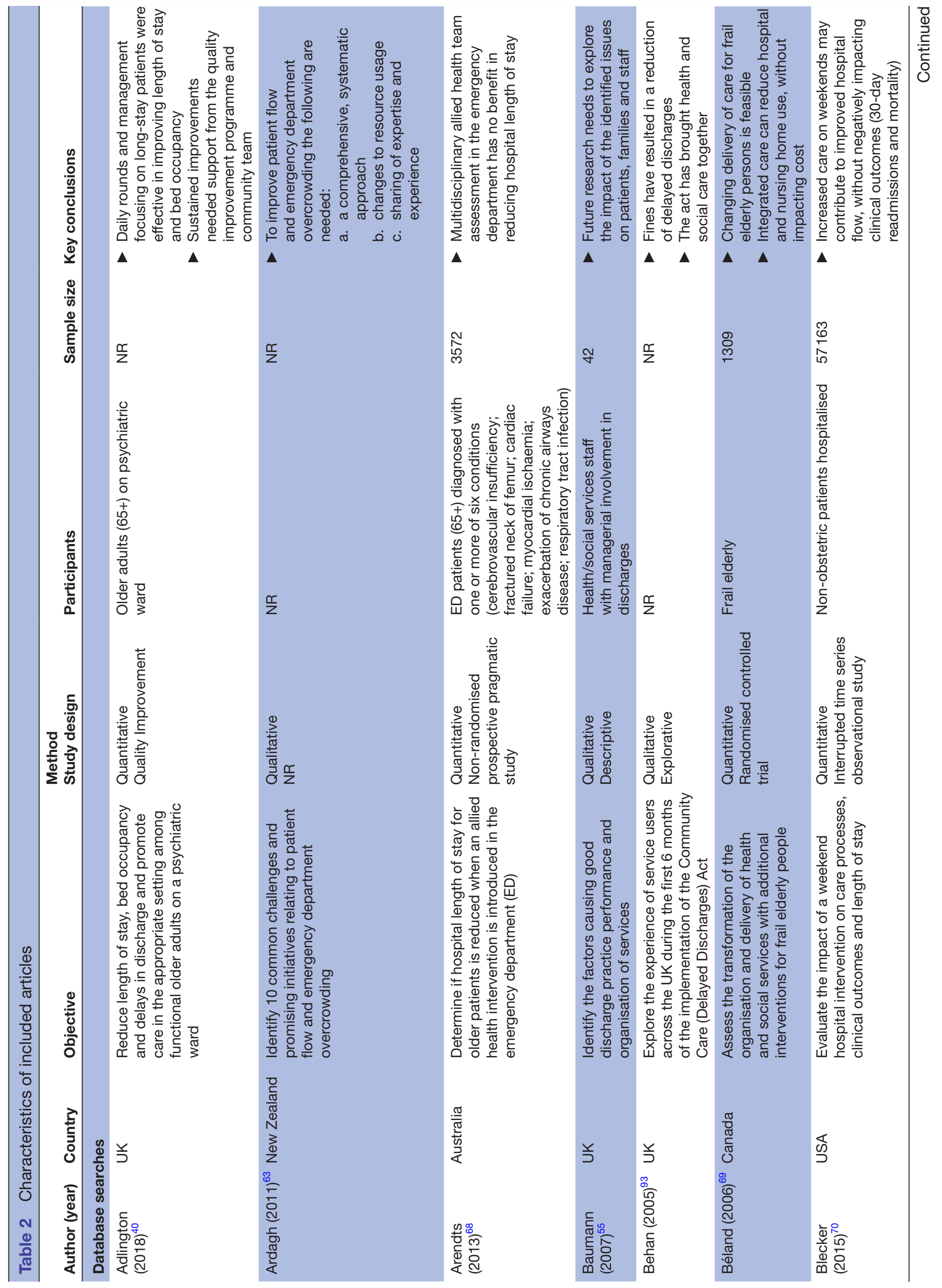




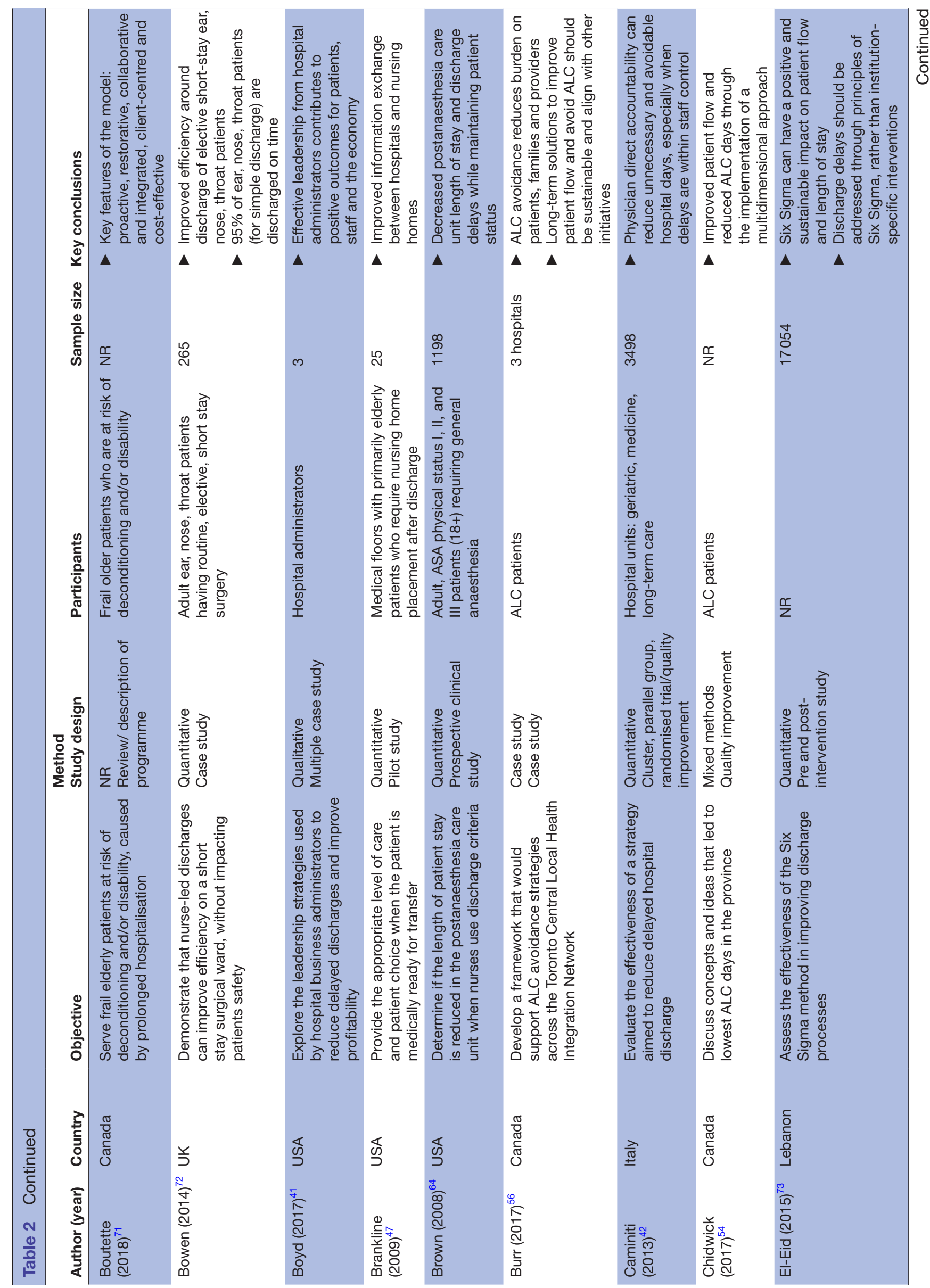




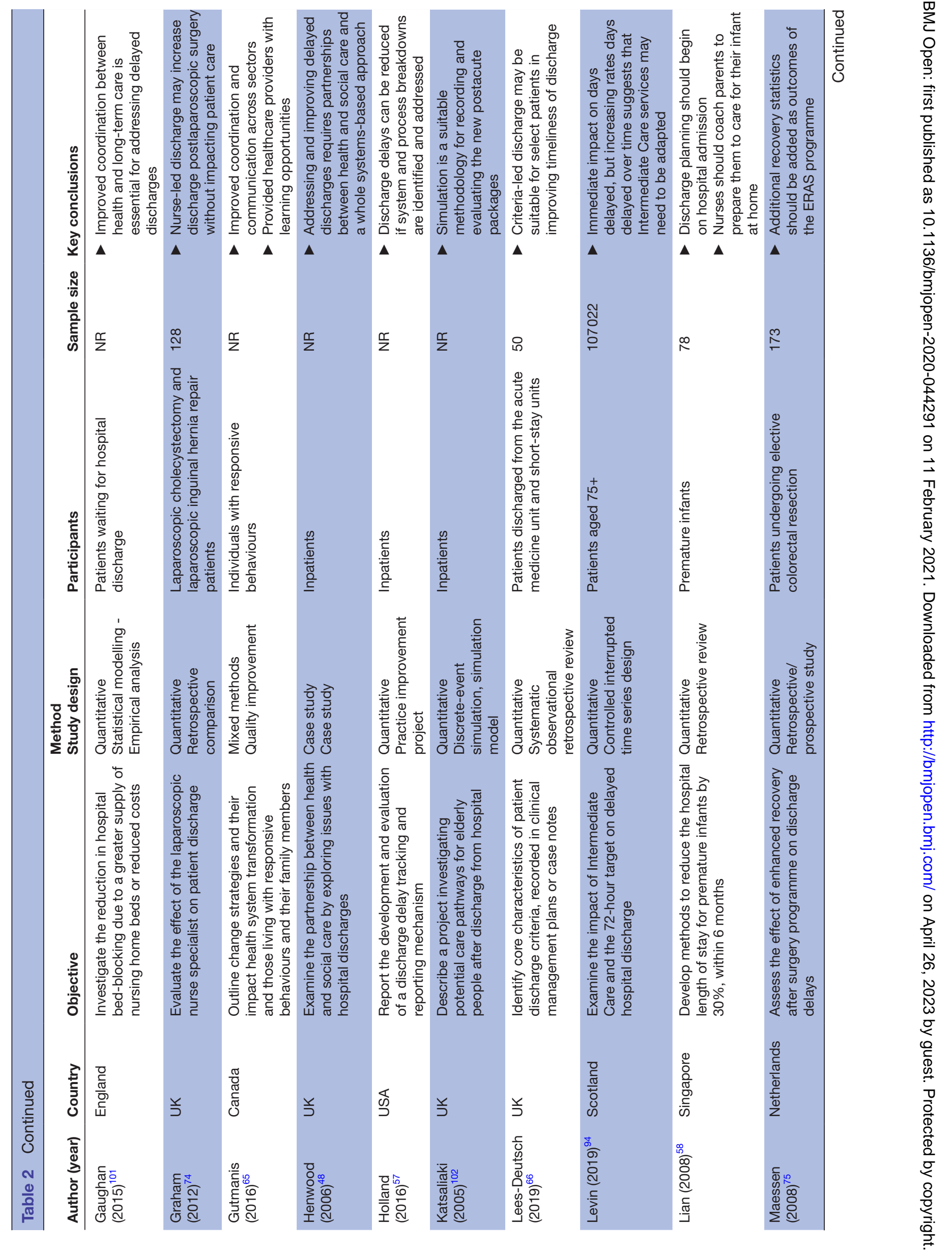




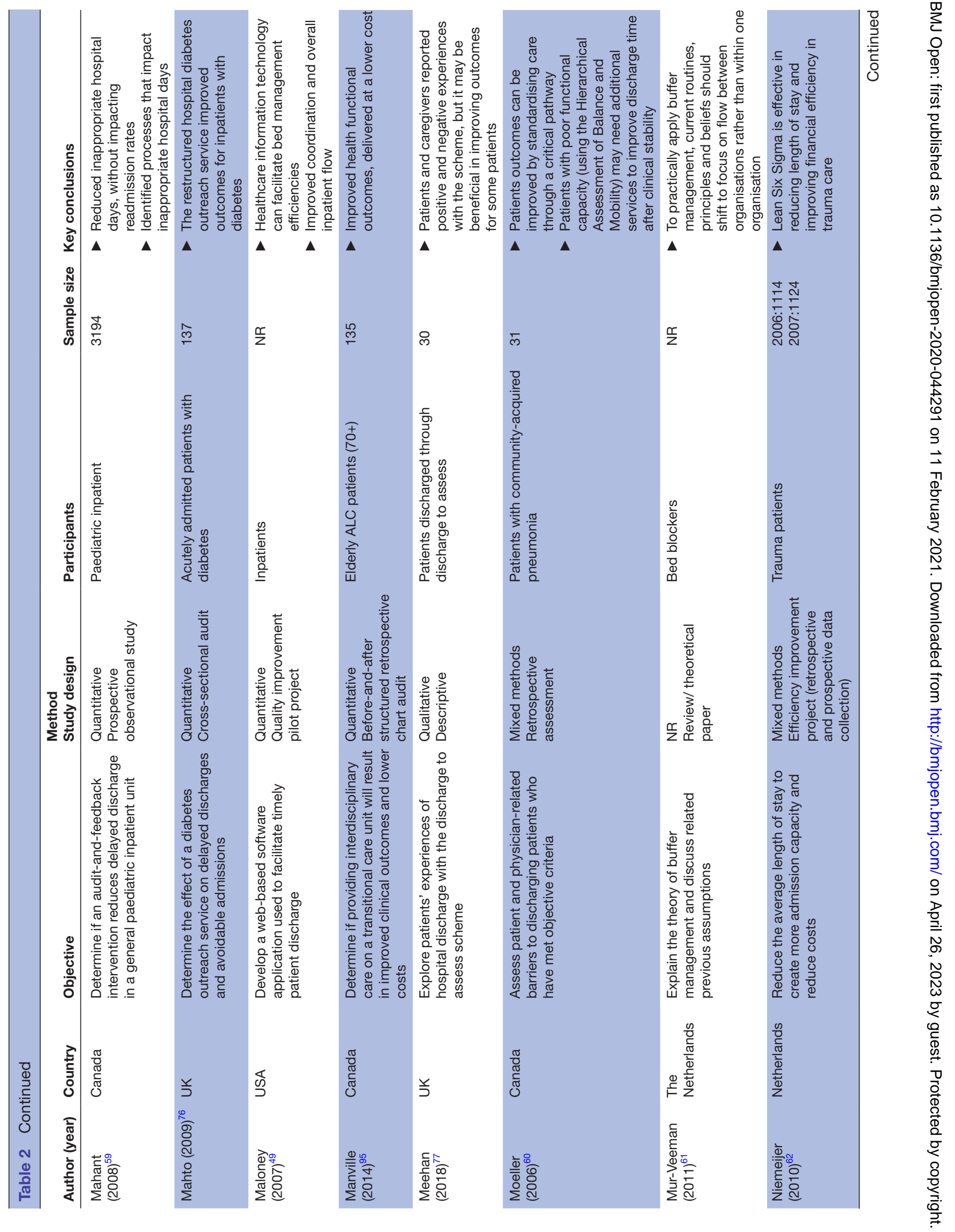




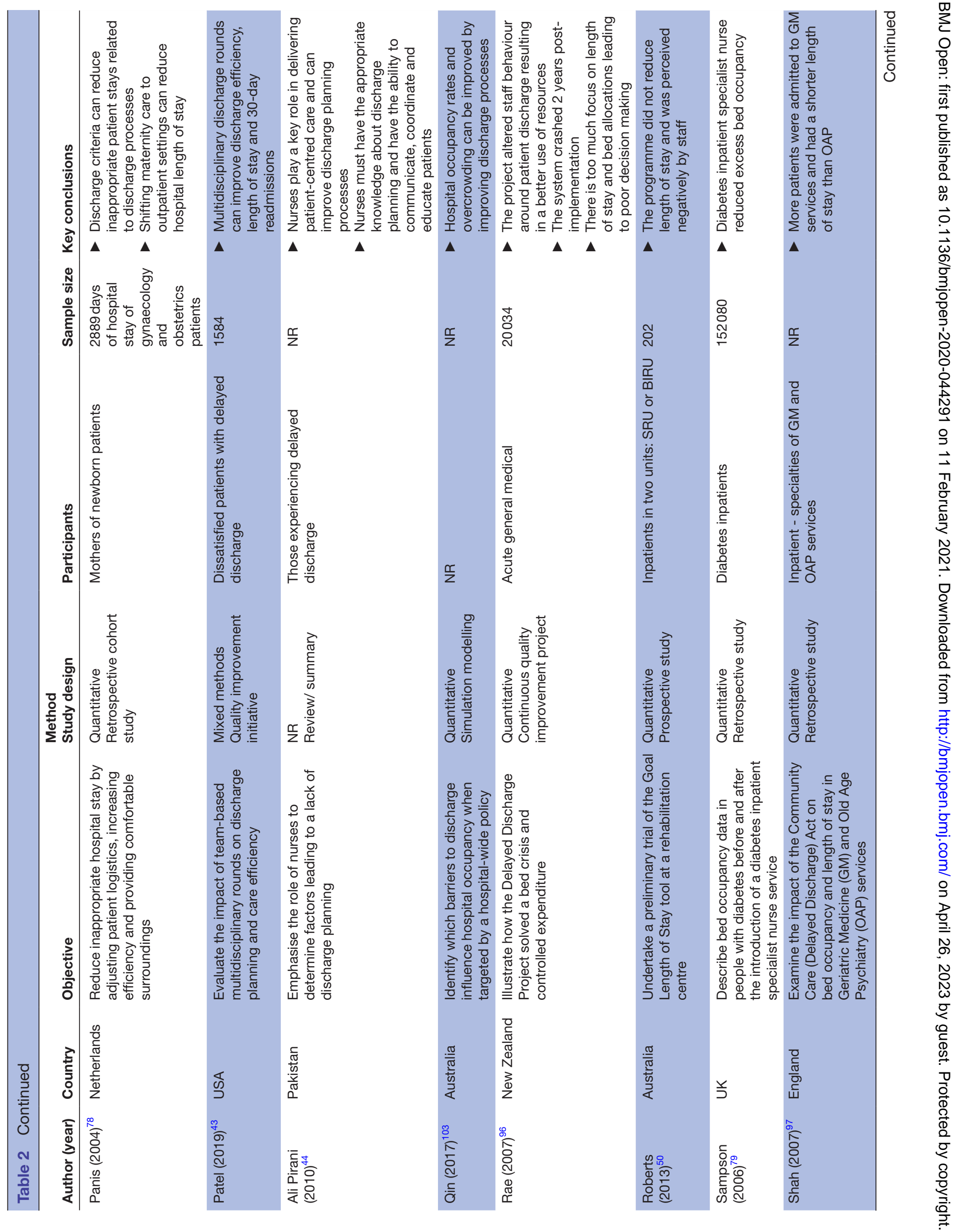




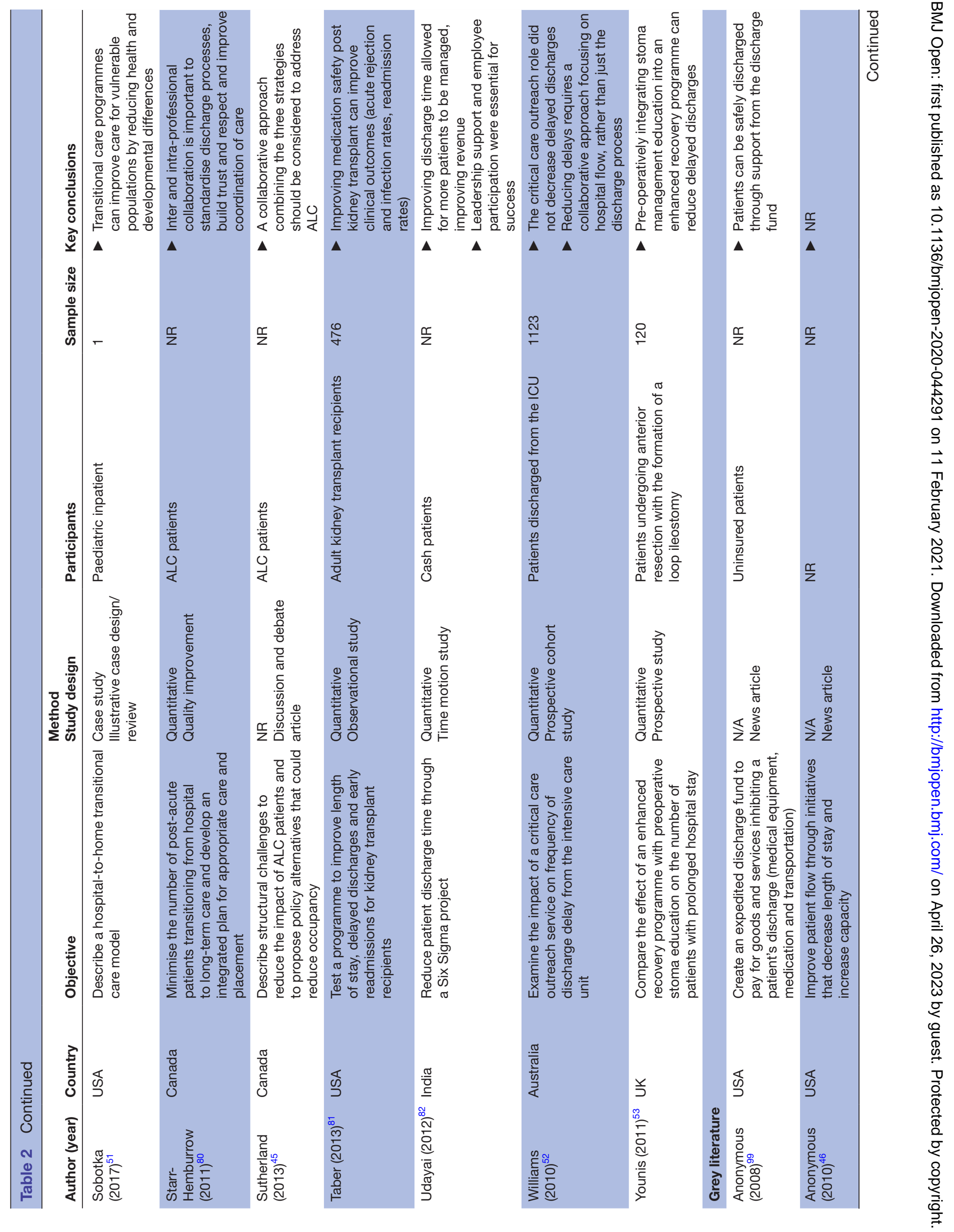




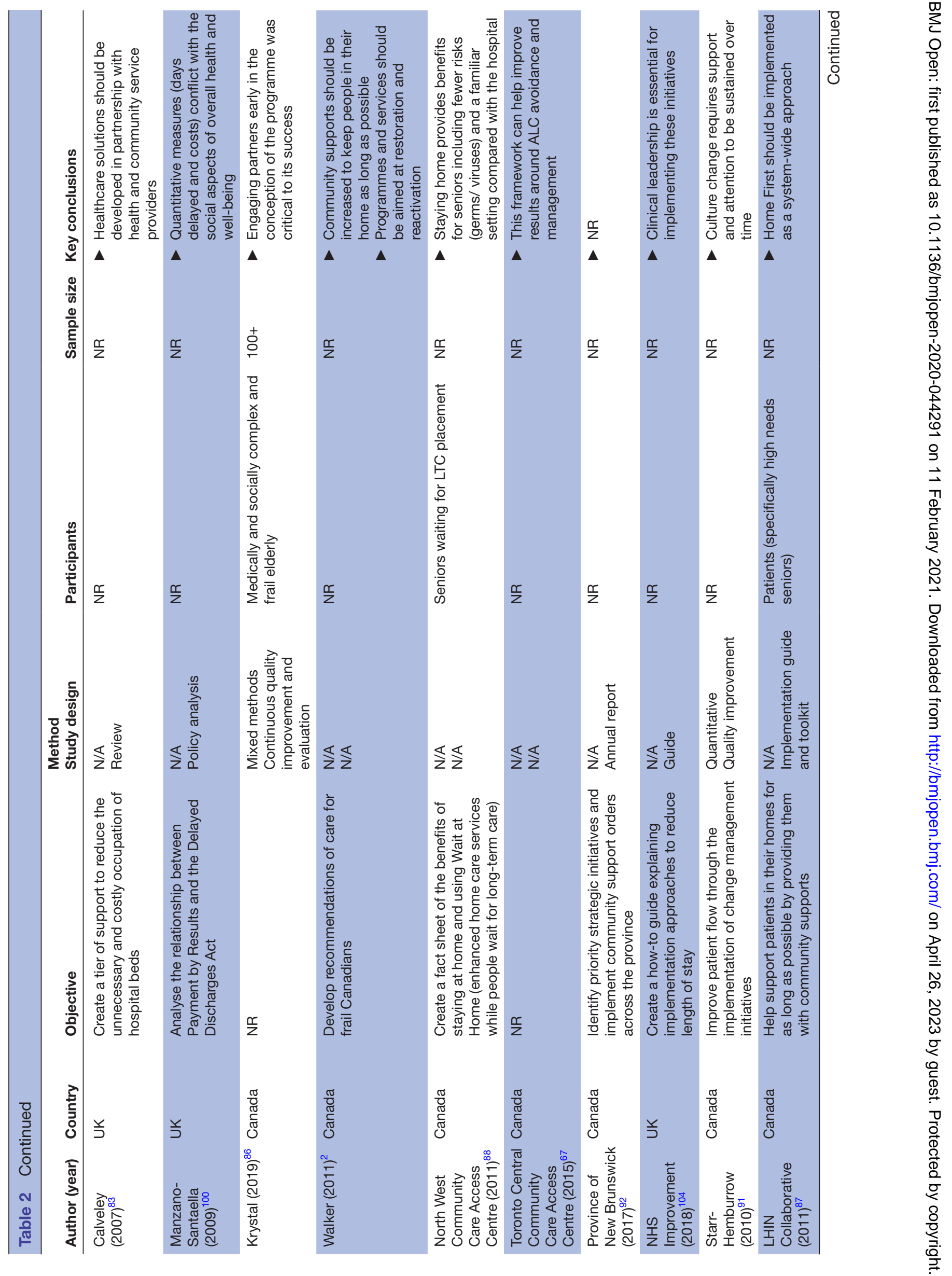




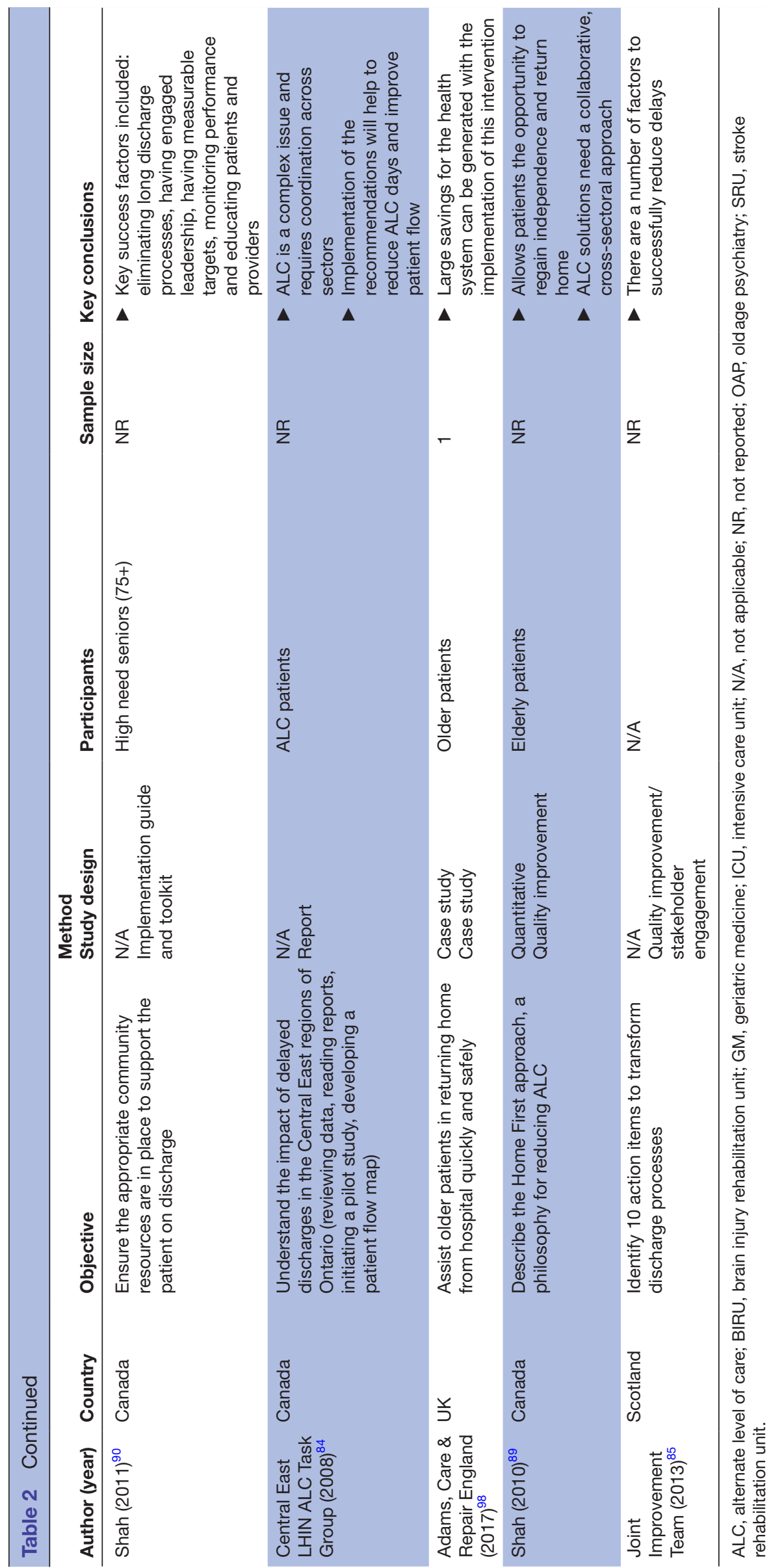




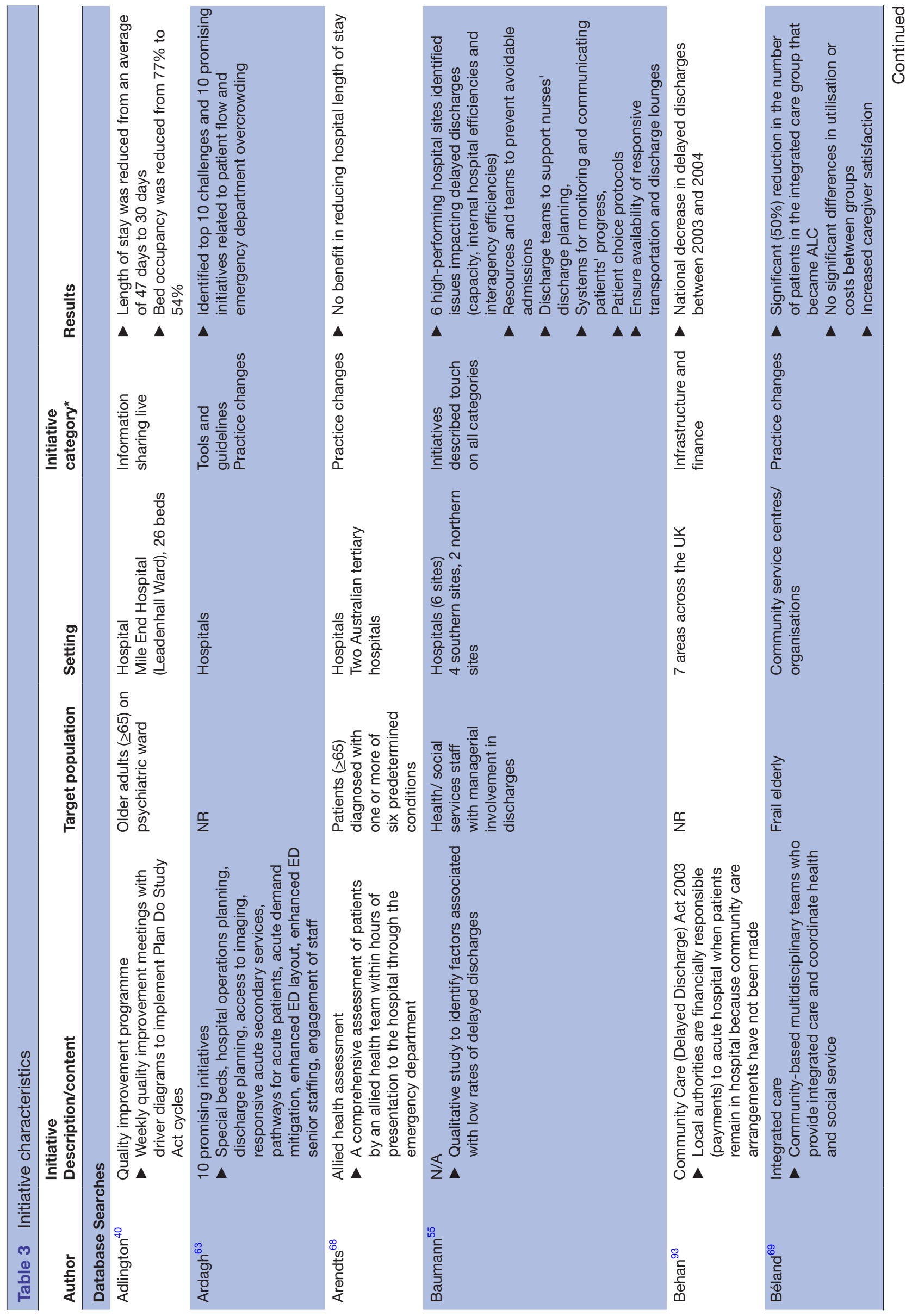




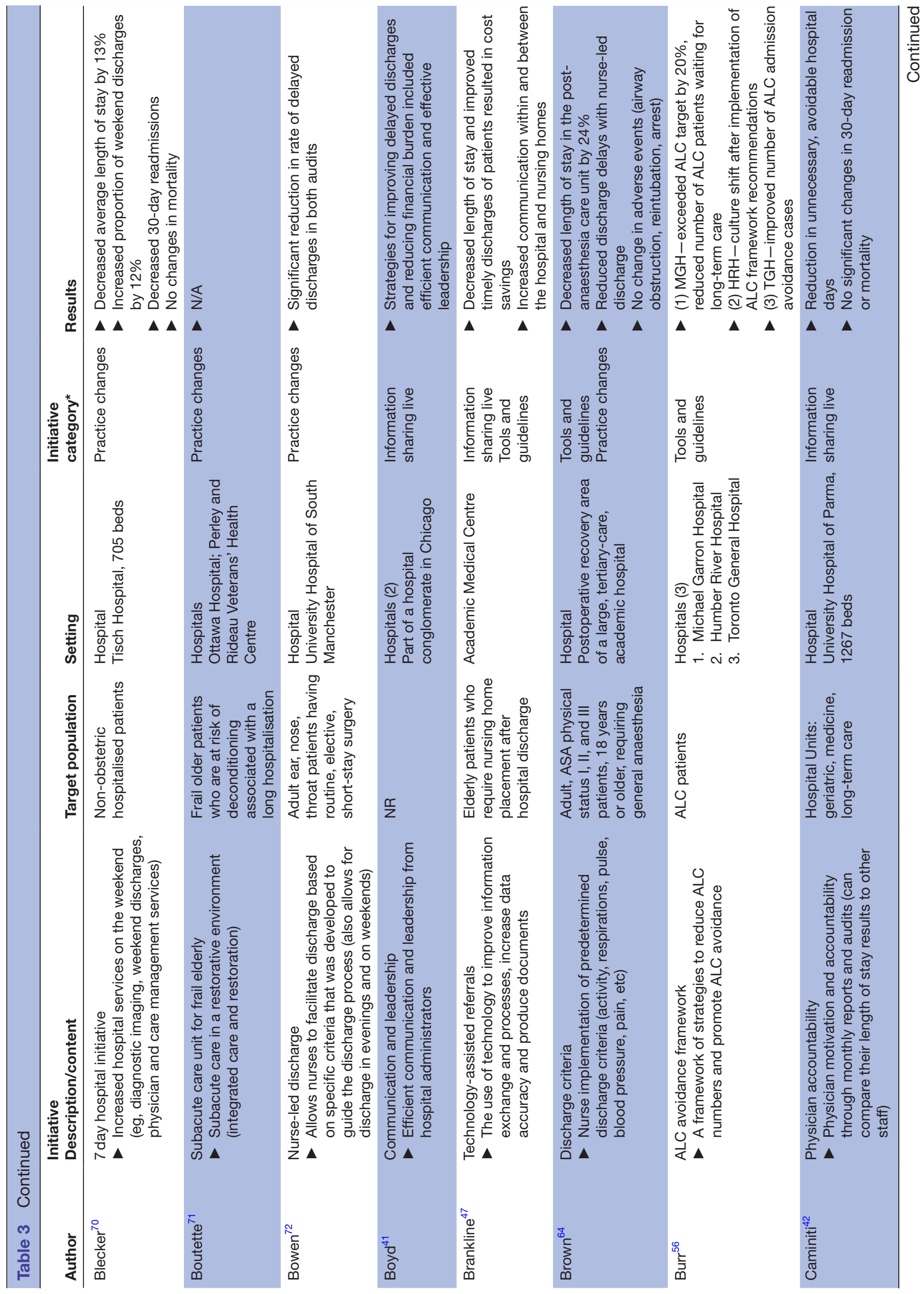




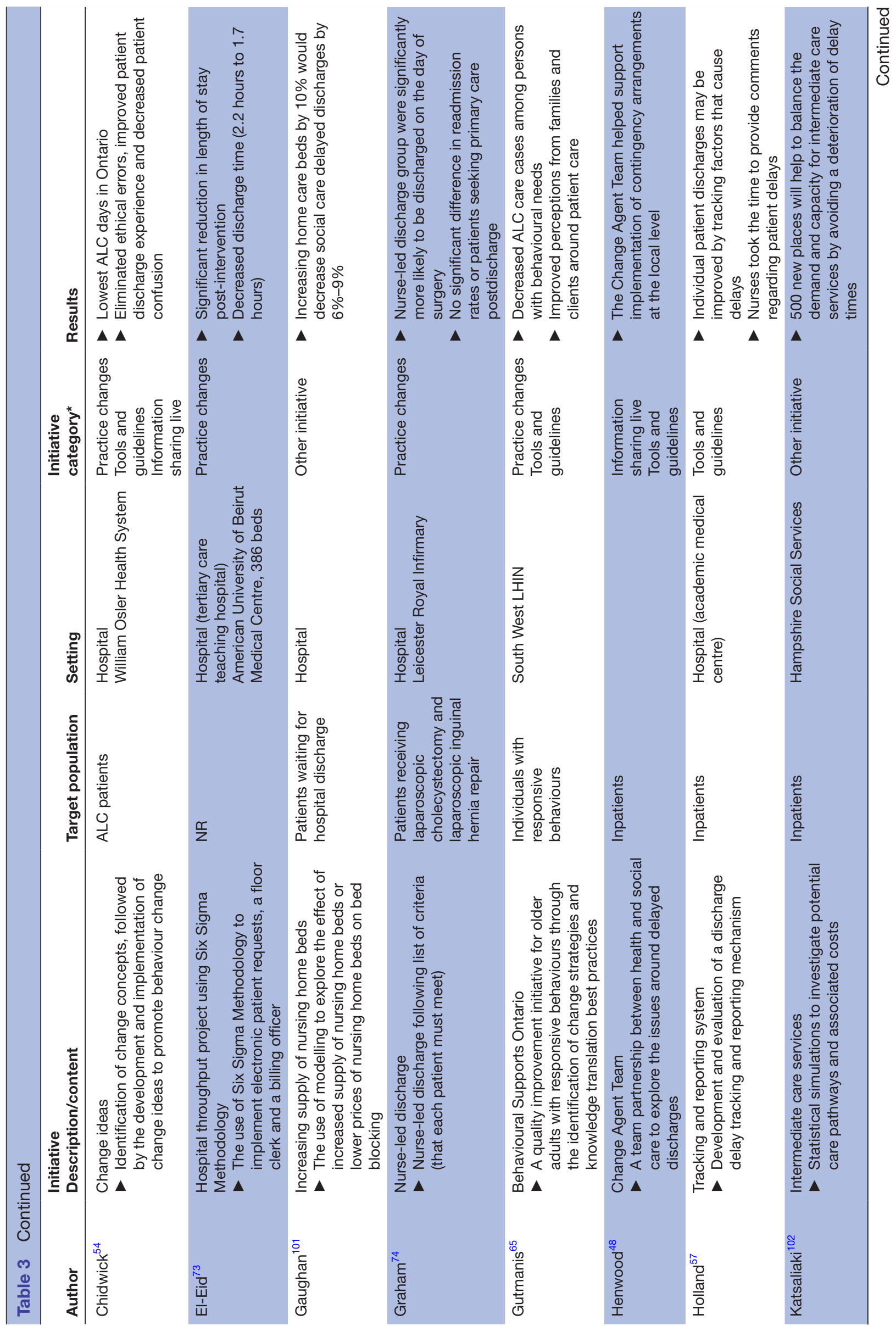




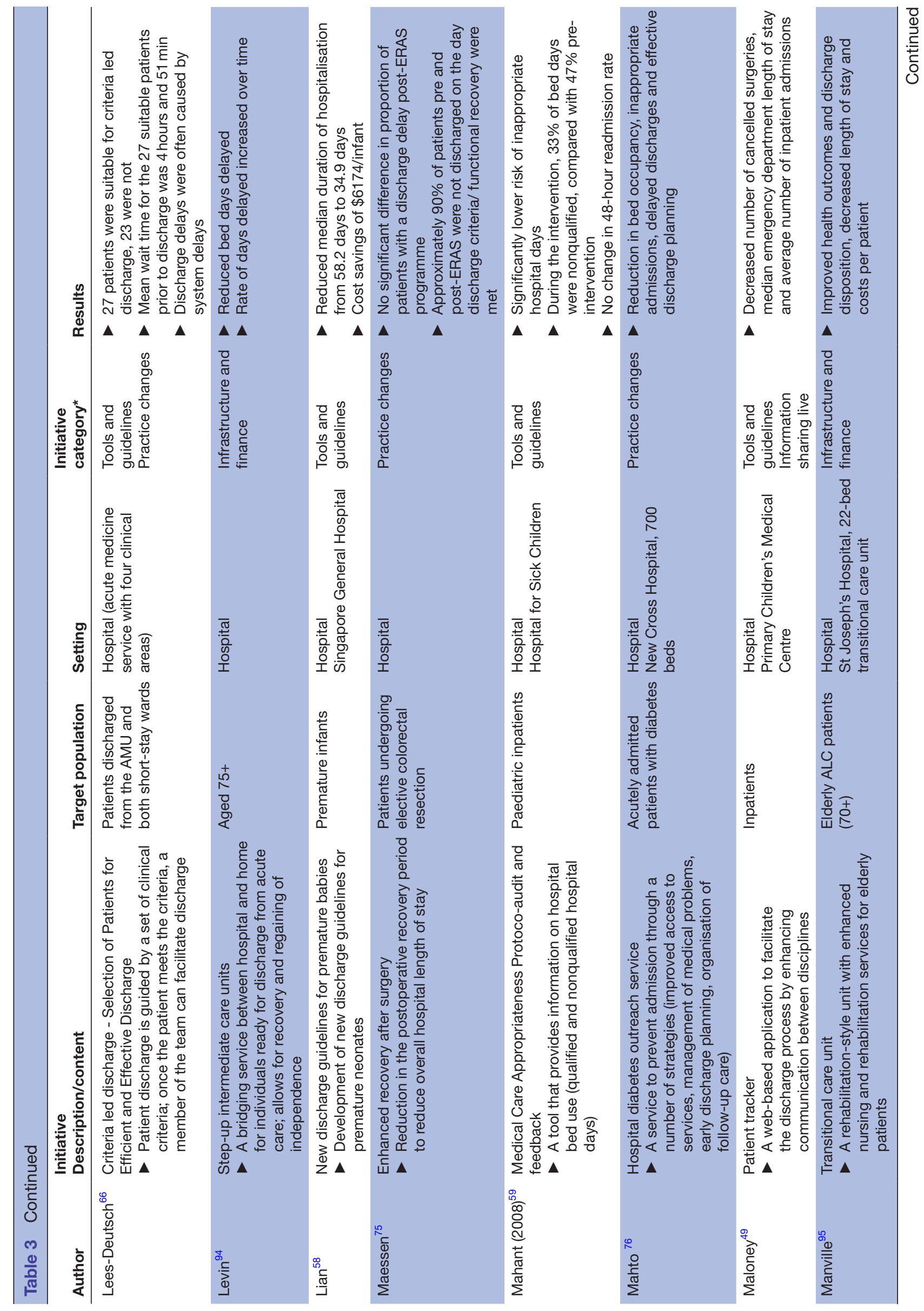




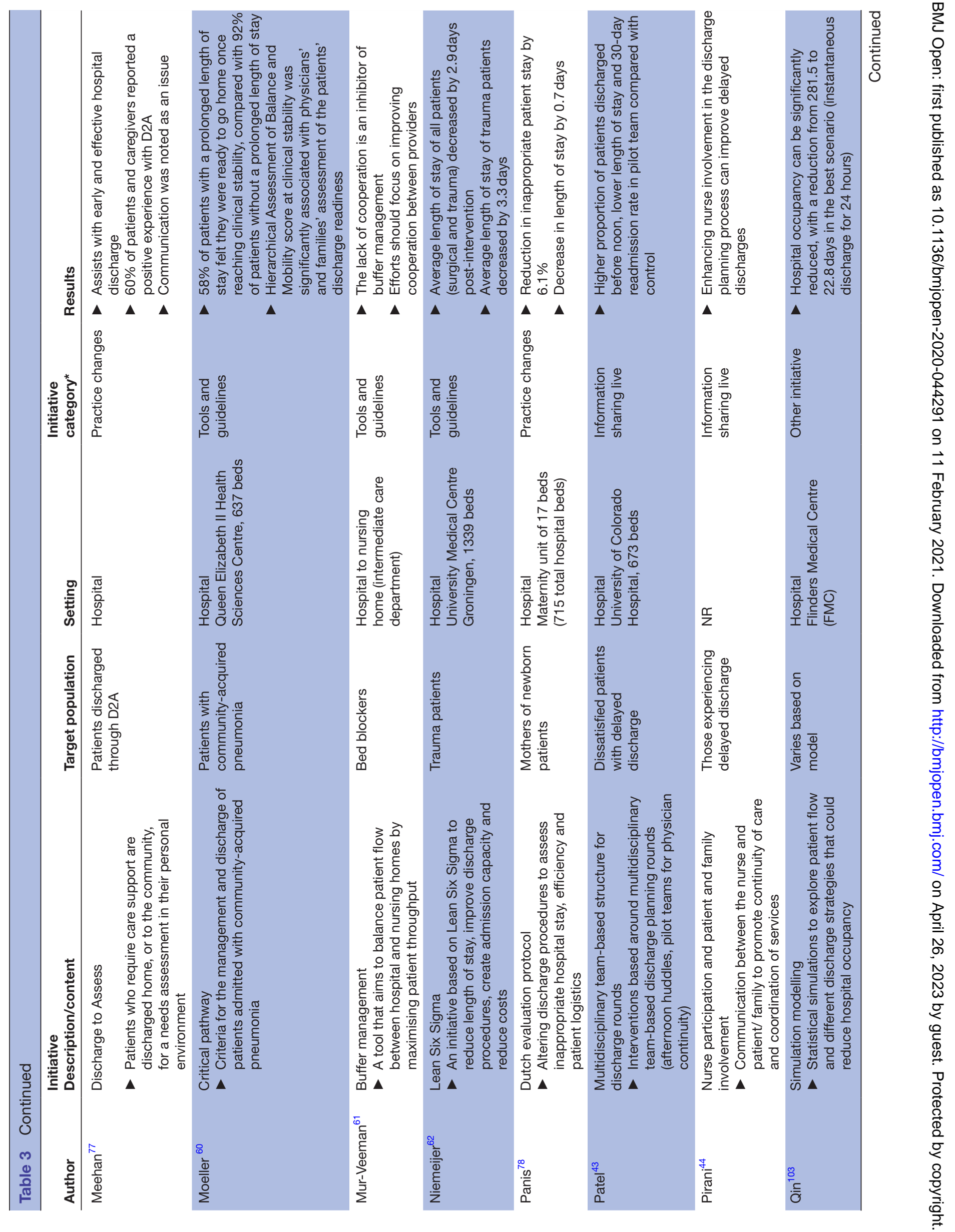




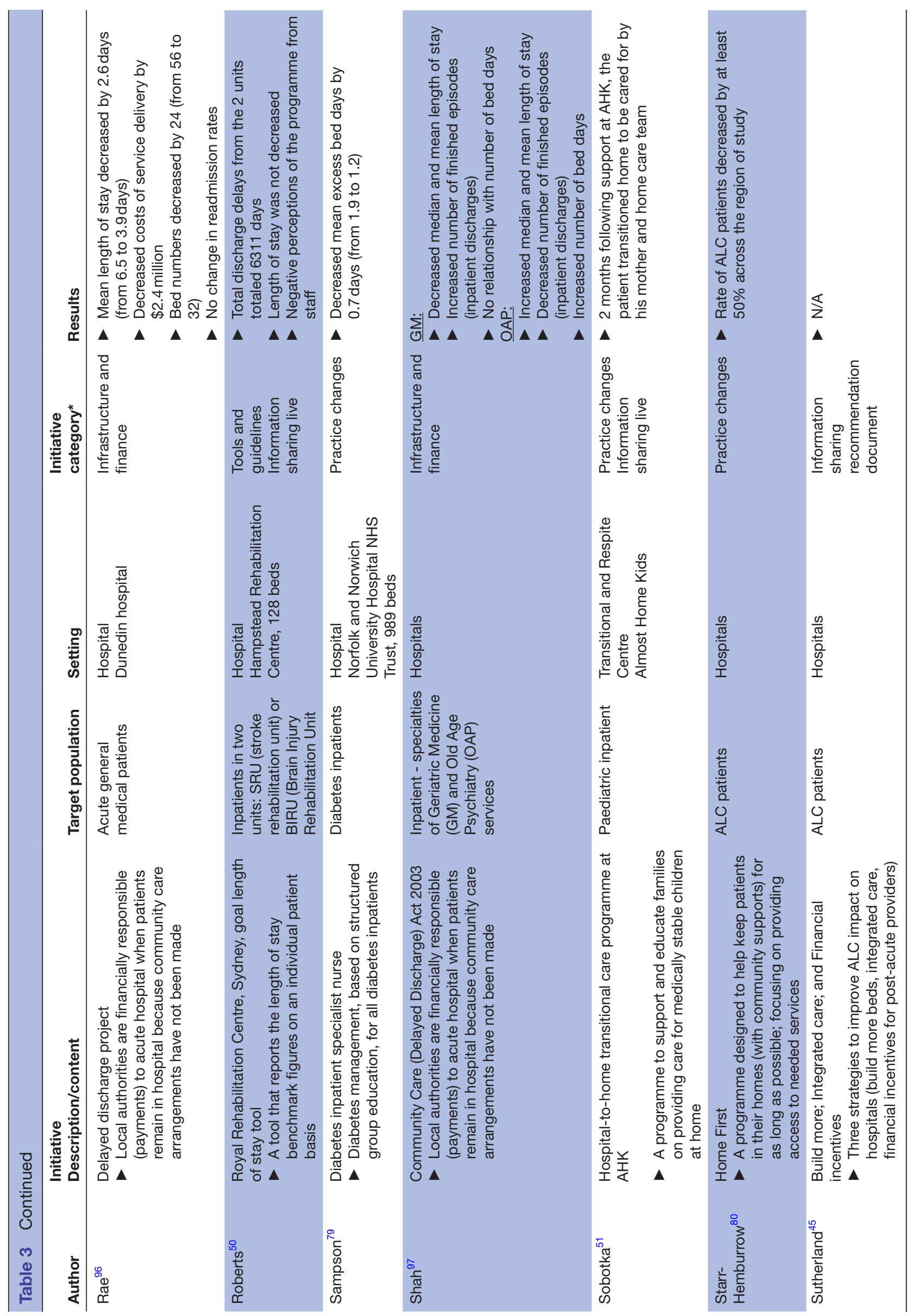




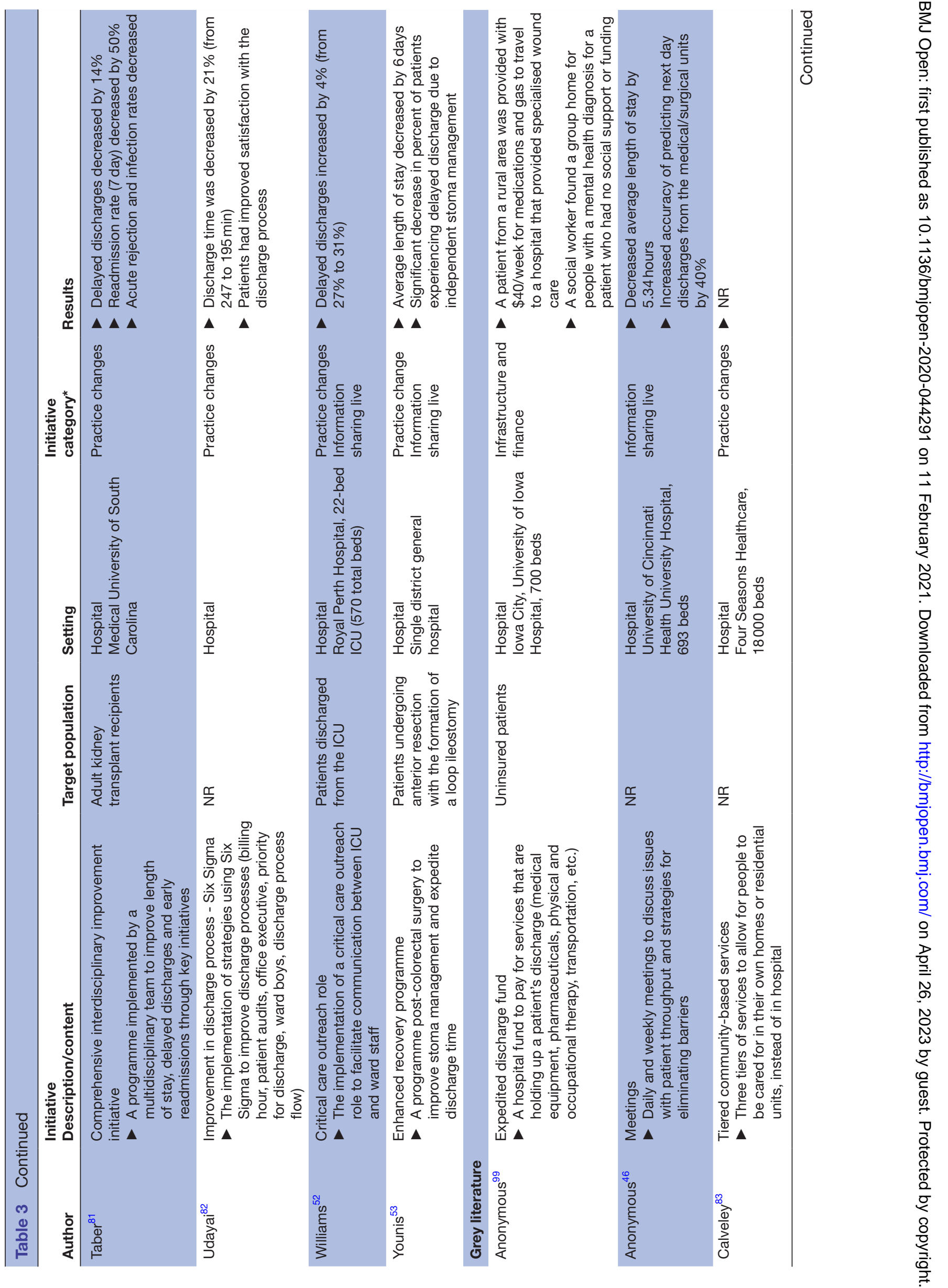




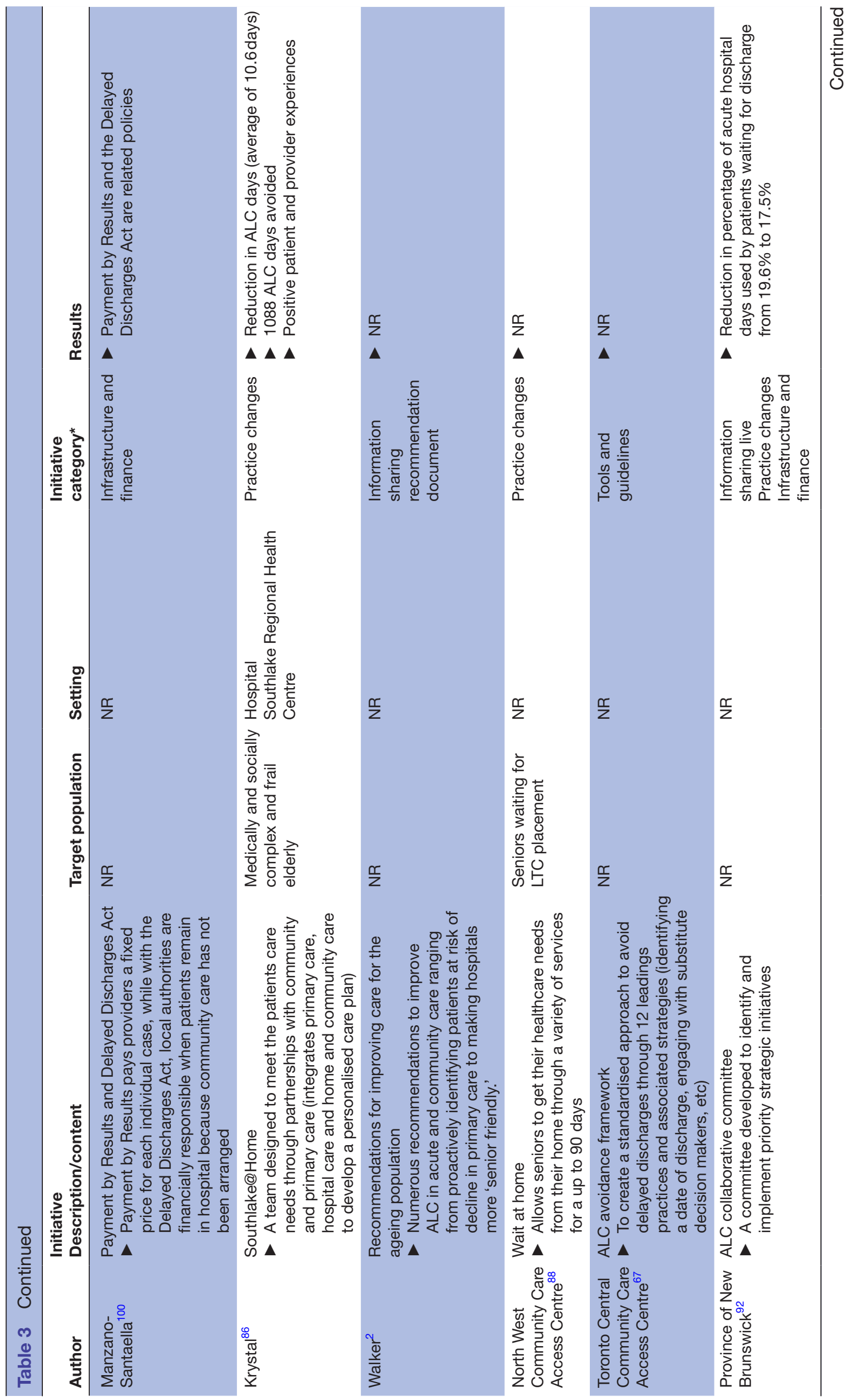




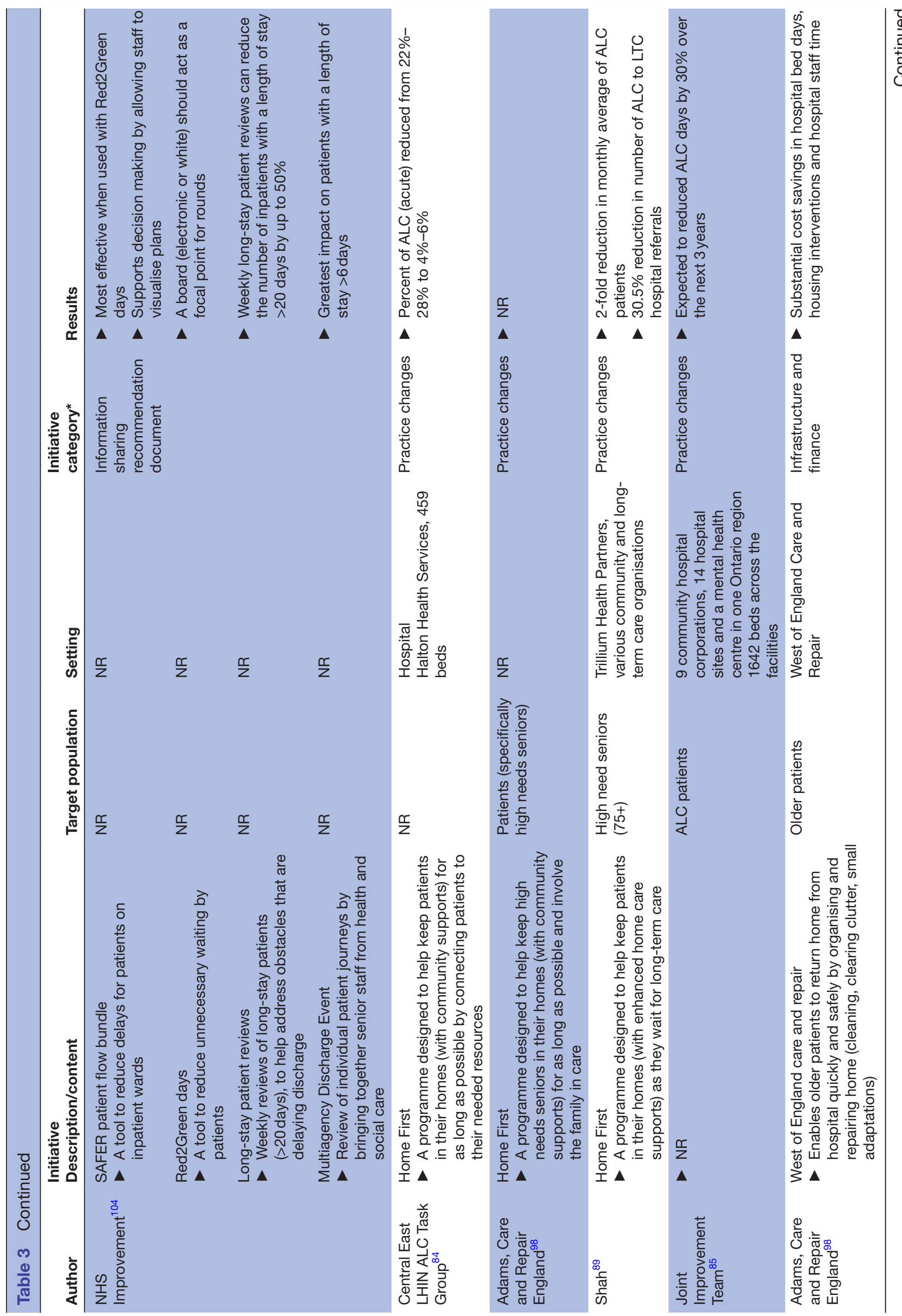



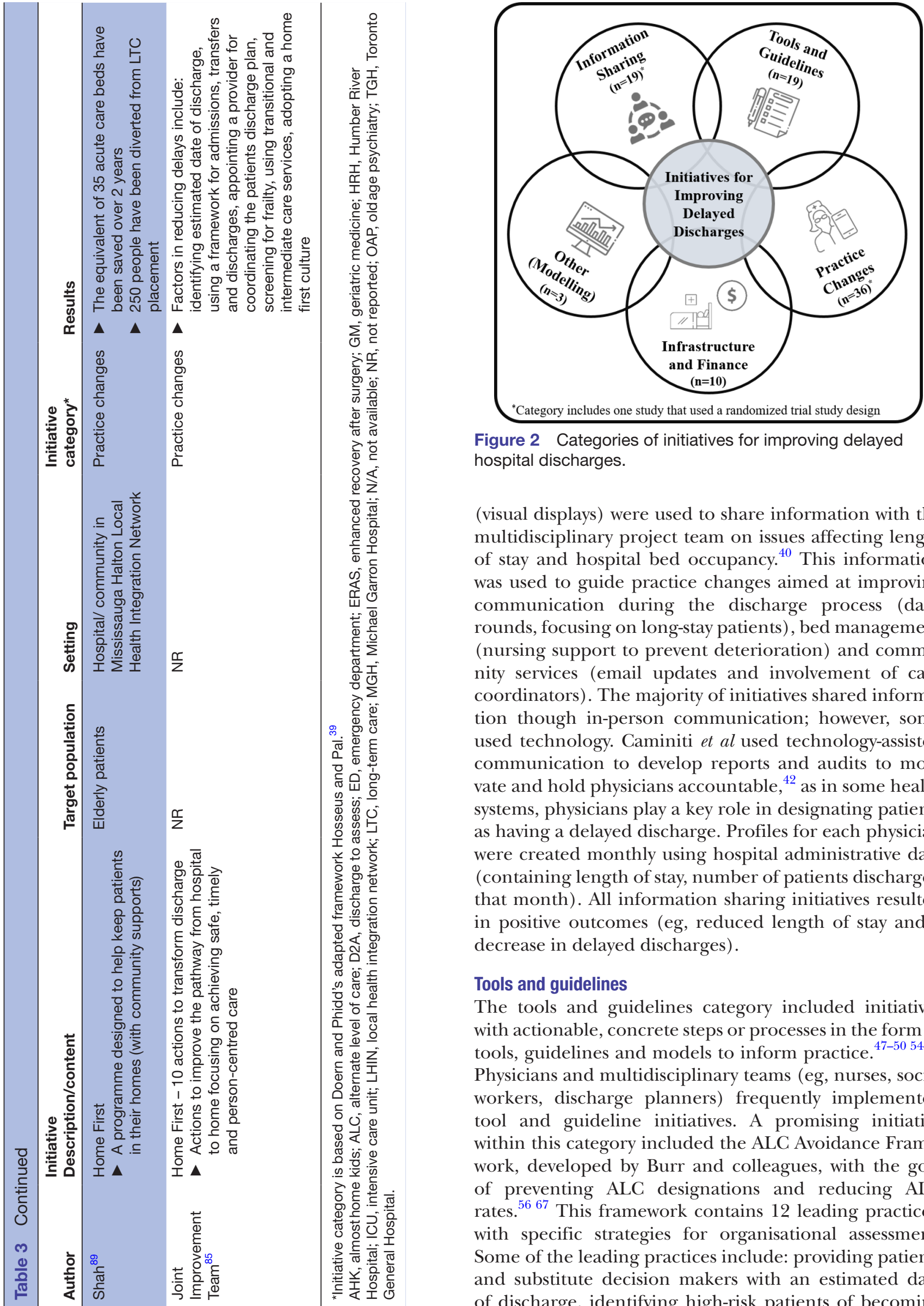
ALC and implementing escalation processes for the management of ALC challenges. Additional initiatives focused on improving patient flow through criteria-led discharges (discharging patients once a predetermined set of criteria had been met) and critical pathways/ discharge guidelines.

The majority of initiatives categorised as tools and guidelines had positive results, ${ }^{47-49}$ 54-60 62 64-66 which included a reduction in hospital days and length of stay. However, one initiative, the Goal Length of Stay Tool, did not have positive outcomes on length of stay. ${ }^{50}$ This initiative incorporated information sharing into a computerbased programme to identify patients whose length of stay exceeded their benchmark figure. It had no change on length of stay and was perceived negatively by staff because they did not believe the benchmark figure was an accurate representation of a patient's current functional status and readiness for discharge.

\section{Practice changes}

This category included initiatives that altered how usual care was delivered. ${ }^{51-5563-6668-92}$ Common practice change initiatives included hospital-based, nurse-led discharges and cross-sectoral transitional programmes (eg, Home First, Discharge to Assess, Hospital to Home). Most were implemented by nurses and multidisciplinary teams. Nurse-led and criteria-led discharges often involved a predetermined list of criteria (clinical parameters) that a patient was required to meet in order to be discharged from hospital by a member of the discharge team. For example, Graham et al conducted a retrospective study $(\mathrm{N}=128)$ to compare nurse-led and doctor-led discharge (standard discharge pathway) postlaparoscopic surgery. ${ }^{74}$ For nurse-led discharge, the patient had to meet 13 preestablished criteria (stable vital signs and comparable to baseline on admission; achieved optimal mobility; minimal nausea, vomiting and dizziness; adequate pain control; received written and verbal instructions about postoperative care, etc). When compared with the doctor-led discharge group $(n=64)$, patients in the nurse-led group $(\mathrm{n}=64)$ were significantly more likely to be discharged on the day of surgery. Incomparing reasons for the success of the nurse-led model, the authors did not tieit to patient factors but rather the ready availability of the nurse specialistwho was able to implement the clearly outlined discharge criteria (specific fornurse-led discharge) much more quickly than the doctor-led group (who did not use suchcriteria).

Another unique example of a practice change initiative was the 7-day Hospital Initiative implemented by Blecker et $a .^{70}$ The purpose of this observational study was to evaluate the impact of increasing weekend staff (hospitalists, care managers, social workers) and services on length of stay, percent of patients discharged on weekends, 30-day readmission rate and in-hospital mortality rate. This multifaceted intervention resulted in a decreased average length of stay, an increased proportion of weekend discharges and no impact on readmission rates or mortality.

The majority of initiatives categorised as a practice change resulted in positive outcomes on length of stay and rate of discharge delays. However, there were several initiatives that were perceived negatively by patients, ${ }^{77}$ or had no change ${ }^{6875}$ or a negative impact ${ }^{52}$ on study outcomes (increase in delayed discharges). Meehan et al explored patient experiences with a programme (Discharge to Assess) that discharged patients who were clinically ready but still required support, in order for their needs to be assessed in their own environment (ie, at home). ${ }^{77}$ Negative experiences were described by participants (patients and caregivers) who indicated feeling ignored, had poor communication with their healthcare providers and were not involved in the decision-making process. Negative outcomes were also identified in Williams et al prospective cohort study. ${ }^{52}$ This study evaluated the impact of a critical care outreach role on delays in discharge and identified that discharge delays from the intensive care unit increased over the study period with the implementation of this role. The authors emphasised the importance of a multifaceted and collaborative approach (involving multiple stakeholders/ team members), focusing on patient flow throughout the hospital in order to address the numerous factors impacting delays.

\section{Infrastructure and finance}

The infrastructure and finance category included initiatives that involved tangible structural or financial changes (eg, building more long-term care beds to facilitate the transition of patients out of hospital, financial penalties for remaining in hospital after being medically ready for discharge). ${ }^{55}$ 92-100 The Community Care (Delayed Discharges) Act in the UK was an initiative identified in multiple articles. ${ }^{93} 9697100$ This initiative required local authorities to make payments to acute hospitals when patients could not be discharged because appropriate community care arrangements had not been made. Although this measure was not necessarily enforced, it created incentive for the hospital and community to work together more collaboratively. Additionally, transitional care units ${ }^{94}$ and discharge funds ${ }^{98} 99$ were common initiatives implemented to address delayed discharges among elderly patients. Transitional care units focused on rehabilitation to promote recovery and the regaining of independence, while discharge funds paid for services that were preventing the patient from being discharged or returning home (eg, medical equipment, medications, transportation, home repairs). All initiatives categorised as infrastructure and finance had positive results on study outcomes, including reductions in discharge delays, length of stay and cost. ${ }^{93-98}$

\section{Other initiatives}

The other initiatives category included statistical and predictive modelling of initiatives to improve delayed discharges. ${ }^{101-103}$ These models explored the impact of 
increasing the supply of nursing home beds, ${ }^{101}$ potential care pathways for the elderly and reimbursement costs ${ }^{102}$ and discharge strategies to reduce hospital occupancy. ${ }^{103}$ Gaughan et al's modelling and empirical analysis identified that increasing the supply of long-term care beds can decrease delayed discharges caused by a lack of social care. ${ }^{101}$ Their models further emphasised the importance of communication between hospitals and the long-term care sector to reduce social care delayed discharges. Similarly, Katsaliaki et al used discrete-event simulations to determine care pathways and associated costs, in which they identified that adding new beds in hospital or intermediate care could reduce delay times. ${ }^{102}$

\section{Recommended initiatives: calls to action}

Several articles were not evaluations but reports or reviews consisting of recommended initiatives to address delayed hospital discharges, which often combined a number of the categories illustrated above. ${ }^{2} 4592104$ Sutherland and Crump outlined three key solutions for improving delayed discharges in Canada: building more acute and postacute care beds, increasing integrated care and creating financial incentives to improve the quality, quantity and effectiveness of healthcare. ${ }^{45}$ The authors discussed challenges and limitations to implementing each of these options and emphasised that a potential solution to addressing delayed discharges was to combine the three strategies. Another Canadian report developed recommendations for providing care to the ageing population and those experiencing a delayed discharge. ${ }^{2}$ Walker outlined recommendations for improving primary care, the care continuum and senior friendly acute care, responding to special needs populations (eg, persons with mental health concerns, addiction and neurological conditions, on dialysis or ventilators), and implementing an 'Assess and Restore' model (a programme to help patients maintain or regain functional independence, transition to home and remain in the community for as long as possible).

The NHS improvement (UK) also released a guide in 2019 on reducing long hospital stays. ${ }^{104}$ This guide contained several recommendations for tackling delayed discharges including: a patient flow bundle (a tool to reduce delays for patients on inpatient wards), Red2Green Days (a visual tool to reduce unnecessary waiting by patients by supporting the rounding process), longstay patient reviews (weekly reviews of long-stay patients ( $>20$ days), to help tackle obstacles that are delaying discharge) and multiagency discharge events (review of individual patient journeys by bringing together senior staff from the local health and social care system).

\section{DISCUSSION}

The purpose of this scoping review was to identify best practices for reducing delayed discharges, examine the characteristics of identified initiatives and develop recommendations for future work. Based on the 66 included articles, our findings showed that: (1) initiatives are focused on quantitative outcomes, with limited assessment of the impact on patient, caregiver and provider experiences; (2) the sustainability of initiatives overtime is not measured (3) there is a lack of important contextual information reported (eg, population characteristics, setting, implementation processes) and (4) there are inconsistencies in how delayed discharges are defined.

This review highlighted where the majority of efforts around addressing delayed discharges have been placed. Practice change was the most common categorisation of initiatives $(n=36)$, followed by information sharing $(n=19)$ and infrastructure and finance $(n=19)$. All initiatives categorised as information sharing and infrastructure and finance reported positive outcomes. Despite reporting positive outcomes, many information sharing initiatives promoted communication between staff, with a limited number targeting communication with patients and families. Additionally, there were more initiatives implemented in a single sector (eg, in hospital) in comparison to cross-sectoral initiatives (eg, hospital and home care).

Length of stay was the most common outcome measured in this scoping review, with a limited number of articles exploring patient, caregiver and provider experiences. For example, could it be considered a success if an initiative does not result in a reduced length of stay, but allows patients to obtain broader goals related to their care (ie, being able to return home) or enhance their care experience? Qualitative methods, including the capturing of patient, caregiver and provider experiences, would allow for a deeper exploration and understanding of success from the perspectives of different stakeholders involved in the initiative. ${ }^{105-107}$ Experiential evidence on whether an intervention is working is required. As noted in our review, a tool developed to better understand delayed discharge was deemed irrelevant by care providers who felt that the tool captured the wrong information. ${ }^{50}$ Therefore, capturing providers' experiences and perspectives are essential in understanding effectiveness of strategies as well as uptake. Most articles included in this scoping review used a quantitative study design, with limited articles using mixed methods or qualitative approaches; thus highlighting a key focus for future research.

The majority of initiatives had an intervention or follow-up period of 1 year, but this ranged from 4 months to 3 years. Based on the limited number initiatives with a follow-up period of longer than 1 year $(n=8)$, there is a need for more formal evaluations with longer follow-up periods to measure the sustainability of initiatives over time. For example, Shelton et als Integrated Sustainability Framework consists of five categories of factors associated with the sustainability of interventions across different contexts and settings: outer context (eg, policies, leadership, funding), inner context (eg, culture, mission, funding), intervention characteristics (eg, cost, adaptability, benefit), processes (eg, partnership, training/support, planning, capacity building) and implementer and population characteristics (eg, implementation skills/expertise, attitudes/motivation). ${ }^{108}$ 
Shelton et al recommended prospective, multi-level and mixed methods study designs for studying the impact and sustainability of interventions. Overall, the initiatives included in this scoping review had positive short-term impacts, but it is unclear if these outcomes are maintained over time. This emphasises the need to design and implement interventions with sustainability in mind.

The majority of categories of initiatives resulted in positive outcomes; however, initiatives classified as practice change had the most mixed outcomes (positive, negative and no change). Practice changes often require a greater number of resources and are more complex to implement than static solutions (ie, hosting daily rounds, developing a framework, etc). A recent systematic review (2018) conducted by Geerligs et al identified implementation barriers and facilitators of patient-focused, in-hospital interventions, ${ }^{109}$ highlighting the complex interplay of factors that can impact implementation. Three domains, with the potential to impact the implementation process, were identified: system (environmental context, culture, communication processes and external requirements), staff (commitment and attitudes, understanding and awareness, role identity and skills, ability and confidence) and intervention (ease of integration, face validity, safety and legality and supportive components). Thus, it is important for interventions to be nimble and adaptable to support the changing need of patients, caregivers, providers, organisations and policy contexts over time.

It was also unclear if some initiatives moved problems from one sector to another. For example, adding more intermediate care beds may alleviate pressures in acute care in the short-term but eventually also be at full capacity if community resources are not available. The 7-day hospital discharge initiative highlighted in this review, improved hospital throughput but had no impact on re-admissions, ${ }^{70}$ suggesting that thinking beyond one sector is required. It is encouraging that most practice change initiatives resulted in improved outcomes, but more clarity is needed to understand what the trade-offs were, as well as how to scale-up the successful initiatives.

Health systems also need to consider their broader goals around delayed hospital discharge-should it only be about reducing delays or should we place an equal focus on optimising patient and caregiver experiences and outcomes? The health system context, including the funding environment, will ultimately shape what interventions get implemented and how they are sustained over time. Some interventions may be considered low value in some countries and contexts and high value in others. Additionally, certain initiatives may be more effective in different environments, as variations in the number of hospital and long-term care beds per capita, infrastructure financing and degree of integration across sectors may impact the outcomes of an initiative. Future research needs to better understand why some strategies may thrive in some environments and not others.

Another key finding identified in the scoping review was the lack of information and details on the implementation strategy (how strategies were implemented, over what time period, how implementation challenges were dealt with), setting (where was it implemented) and population characteristics (who was it implemented for). The implementation of initiatives can be impacted by differences in healthcare system structure and funding. Further, this contextual information is essential for both understanding outcomes, scaling-up and sustainability of interventions because it is not only important to know if the intervention was effective, but also for whom and in what context it was effective. ${ }^{110} 111$

Finally, this review highlighted a lack of consistency in how delayed discharge was defined, both within and across countries. While there was one definition that was used more frequently (a patient was identified as medically ready/fit for discharge, but remained in hospital), there can be different interpretations of when a patient is considered 'medically fit' and who makes this decision. Inconsistent definitions can lead to variations in the reported rates of delayed discharge, which can further impact the perceived applicability and effectiveness of an intervention. Our finding was echoed in a narrative review conducted by Glasby et al, who further explained the challenges differing definitions create when attempting to compare findings. ${ }^{112}$ In order to mitigate these challenges, it is critical to be more consistent around how delayed discharges are defined.

\section{Future work}

From this review, we have identified areas for future research. First, patient, family and provider needs and experiences should be explored during the development and implementation of initiatives aimed at improving delayed discharges. Patient and family engagement is both important and recommended by healthcare and government organisations; however, they are often excluded in the development and write-up of best practice guidelines. ${ }^{113}$ Second, evaluation studies that track outcomes over a longer period of time should be conducted to study the sustainability of initiatives over time, how they are adapted (developmental evaluations), as well as their impact on other sectors (eg, primary and community care). Third, initiatives should be implemented and integrated across sectors (hospital, primary care and home and community care) to help get at the root of the problem and ensure the implementation of an initiative in one setting does not simply shift the problem to another. Fourth, a review should be conducted to assess the state of knowledge around initiatives that are more upstream in nature (eg, hospital admission avoidance, emergency department diversion and delivery models that proactively address the health and social care needs of individuals in community settings). Finally, there is an opportunity for future research to consider a realist review of the literature on delayed hospital discharge to understand the context, mechanisms of impact, outcomes and theories of change, given that addressing a delayed discharge is a complex problem. As a first step, we sought to include 
interventions that included hospitals, and this revealed a single sector and reactive approach to addressing delayed discharge.

\section{Limitations}

There are a few limitations of this review that should be noted. It is possible that some relevant articles were missed because the search was limited from 1 January 2004 and 16 August 2019 and conducted in English. Our search strategy was comprehensive and we conducted an in-depth search of grey literature to minimise the potential of missed articles. While we did not limit the inclusion of articles to the English language, our search strategy was in English, so there is a possibility that articles published in different languages were not identified. We excluded studies that changed the threshold/timing of discharge (early discharge), as they often focused on cost-savings. We acknowledge that some of these initiatives may have transferable lessons to address discharge delays, and thus, note their exclusion as a potential limitation of this review. Although it is not a requirement for scoping reviews, ${ }^{36}$ the interventions in this review were not critically appraised, and thus, we cannot make recommendations on which interventions should be scaled up. Given concerns with regression toward the mean, especially for quality improvement projects, any positive results need to be interpreted with caution. Health systems are complex, evolving environments, where various iterations of strategies are regularly implemented, but not necessarily formally reported or published. Future work by our team will include a process evaluation on how strategies are actually implemented in different health system contexts, as well as why they work or do not work.

\section{Ethical considerations}

There are a few ethical concerns associated with scoping reviews to be noted. These concerns include authorship, transparency and plagiarism. All authors met the International Committee of Medical Journal Editors' recommended criteria for authorship and author order was based on overall contribution to the review. We clearly outlined our methods at each stage of the scoping review to ensure transparency and replicability. We also acknowledged individuals who contributed to the review, but who did not warrant authorship. Lastly, when reporting the results of individual studies, we wrote them in our own words and cited appropriately to avoid plagiarism.

\section{CONCLUSIONS}

This scoping review identified a variety of initiatives addressing delayed discharges across five categories: information sharing, tools and guidelines, practice changes, infrastructure and finance and other. The majority of initiatives were focused on practice changes and many incorporated more than one category. Initiatives were often implemented in a single sector, rather than across sectors. It appears that many strategies implemented in hospitals including communication huddles, nurse-led discharges, home first programmes and building more infrastructure had positive short-term impacts. Many initiatives that led to positive outcomes were implemented by a multidisciplinary team and included a number of components (eg, monthly reports and education). The success of these initiatives is based on a service-led definition of success (effective use of hospital resources), rather than success from the patient and family perspective. This highlights the need to shift to a more patient-centred approach that focuses on improving outcomes and experiences, rather than system and hospital outcomes (ie, length of stay and hospital occupancy) alone. Despite the number of unique initiatives aimed at addressing delayed discharges, current strategies may not be getting at the root of the problem (initiatives/intervention prior to hospital admission) and there is a need for solutions to this problem that have a long-term and sustainable impact.

\section{Author affiliations}

${ }^{1}$ Institute for Better Health, Trillium Health Partners, Mississauga, Ontario, Canada ${ }^{2}$ Leslie Dan Faculty of Pharmacy, University of Toronto, Toronto, Ontario, Canada ${ }^{3}$ Rehabiliation Sciences Institute, University of Toronto, Toronto, Ontario, Canada ${ }^{4}$ Institute of Health Policy, Management and Evaluation, Dalla Lana School of Public Health, University of Toronto, Toronto, Ontario, Canada

${ }^{5}$ Quality Division, Ontario Health, Toronto, Ontario, Canada

${ }^{6}$ Centre for Health Services and Policy Research, School of Population and Public Health, University of British Columbia, Vancouver, British Columbia, Canada ${ }^{7}$ School of Social Policy, University of Birmingham, Edgbaston, Birmingham, UK ${ }^{8}$ Department of Family and Community Medicine, University of Toronto, Toronto, Ontario, Canada

${ }^{9}$ MAP Centre for Urban Health Solutions, St. Michael's Hospital, Toronto, Ontario, Canada

\section{Twitter Kristina Marie Kokorelias @kmkokorelias}

Acknowledgements The authors would like to thank the University of Toronto librarian for their contribution to the search strategy, as well as Juliane Koropeski (JK) and Maliha Asif (MA) for their help screening articles. We would like to thank the involvement of our stakeholders who provided feedback on our search terms and sent us grey literature. Lastly, we would like to thank our Alternate Level of Care Advisory Council and Ida McLaughlin (chair of council) for their continual support and feedback on this programme of work.

Contributors KK, SJTG, JS, JG and TK were responsible for the conception and design of the study, as well as acquisition of funding for the study. LC, SJTG, KMK and KK led the screening of articles and the analysis and interpretation of data, but all authors contributed to the analysis and interpretation. Drafts of the manuscript were reviewed and revised by all authors. All of the authors read and approved the final manuscript.

Funding This work was supported by the Canadian Institutes of Health ResearchTransitions in Care Strategic Funding Initiative on Best and Wise Practices (Grant \#163064). KK holds the Dr Mathias Gysler Research Chair in Patient and Family Centred Care. SJTG and TK are funded by the Canadian Institutes of Health Research Embedded Scientist Salary Award on Transitions in Care working with Ontario Health (Quality); the award also supported staff to assist with screening.

Competing interests None declared.

Patient consent for publication Not required.

Provenance and peer review Not commissioned; externally peer reviewed.

Data availability statement All data relevant to the study are included in the article or uploaded as online supplemental information.

Supplemental material This content has been supplied by the author(s). It has not been vetted by BMJ Publishing Group Limited (BMJ) and may not have been peer-reviewed. Any opinions or recommendations discussed are solely those 
of the author(s) and are not endorsed by BMJ. BMJ disclaims all liability and responsibility arising from any reliance placed on the content. Where the content includes any translated material, BMJ does not warrant the accuracy and reliability of the translations (including but not limited to local regulations, clinical guidelines, terminology, drug names and drug dosages), and is not responsible for any error and/or omissions arising from translation and adaptation or otherwise.

Open access This is an open access article distributed in accordance with the Creative Commons Attribution Non Commercial (CC BY-NC 4.0) license, which permits others to distribute, remix, adapt, build upon this work non-commercially, and license their derivative works on different terms, provided the original work is properly cited, appropriate credit is given, any changes made indicated, and the use is non-commercial. See: http://creativecommons.org/licenses/by-nc/4.0/.

\section{ORCID iDs}

Lauren Cadel http://orcid.org/0000-0001-6925-8163

Sara J T Guilcher http://orcid.org/0000-0002-9552-9139

\section{REFERENCES}

1 Bate A. Delayed transfers of care in the NHS, 2017: 1-20.

2 Walker D. Caring for our aging population and addressing alternate level of care: report submitted to the Minister of health and longterm care. Canada, 2011.

3 Rojas-García A, Turner S, Pizzo E, et al. Impact and experiences of delayed discharge: a mixed-studies systematic review. Health Expect 2018;21:41-56.

4 Barnable A, Welsh D, Lundrigan E, et al. Analysis of the influencing factors associated with being designated alternate level of care. Home Health Care Manag Pract 2015;27:3-12.

5 McCloskey R, Jarrett P, Stewart C, et al. Alternate level of care patients in hospitals: what does dementia have to do with this? Can Geriatr J 2014;17:88-94.

6 Walker H, Langton D, Thomson L. 'New to forensic'; implementing a problem-based introductory educational programme for forensic practitioners in Scotland. J Psychiatr Ment Health Nurs 2011;18:934-42.

7 Jasinarachchi KH, Ibrahim IR, Keegan BC, et al. Delayed transfer of care from NHS secondary care to primary care in England: its determinants, effect on hospital bed days, prevalence of acute medical conditions and deaths during delay, in older adults aged 65 years and over. BMC Geriatr 2009;9:4.

8 Rosman M, Rachminov O, Segal O, et al. Prolonged patients' inhospital waiting period after discharge eligibility is associated with increased risk of infection, morbidity and mortality: a retrospective cohort analysis. BMC Health Serv Res 2015;15:246-46.

9 Everall AC, Guilcher SJT, Cadel L, et al. Patient and caregiver experience with delayed discharge from a hospital setting: a scoping review. Health Expect 2019;22:863-73.

10 Amy C, Zagorski B, Chan V, et al. Acute care alternate-level-of-care days due to delayed discharge for traumatic and non-traumatic brain injuries. Healthc Policy 2012;7:41-55.

11 Hwabejire JO, Kaafarani HMA, Imam AM, et al. Excessively long Hospital stays after trauma are not related to the severity of illness: let's aim to the right target! JAMA Surg 2013;148:956-61.

12 Challis D, Hughes J, Xie C, et al. An examination of factors influencing delayed discharge of older people from hospital. Int $J$ Geriatr Psychiatry 2014;29:160-8.

13 Costa AP, Hirdes JP. Clinical characteristics and service needs of Alternate-Level-of-Care patients waiting for long-term care in Ontario hospitals. Healthc Policy 2010;6:32-46.

14 Costa AP, Poss JW, Peirce T, et al. Acute care inpatients with longterm delayed-discharge: evidence from a Canadian health region. BMC Health Serv Res 2012;12:172.

15 Kozyrskyi A, De Coster C, St John P. Long stay patients in Winnipeg acute care hospitals. Healthc Manage Forum 2002;Suppl:15-20.

16 Lorenzo RD, Formicola V, Carra E, et al. Risk factors for long-stay in an Italian acute psychiatric ward: a 7-year retrospective analysis. $J$ Nurs Educ Pract 2013;4:p68.

17 Rogers A, Clark EH, Rittenhouse K, et al. Breaking down the barriers! factors contributing to barrier days in a mature trauma center. J Trauma Acute Care Surg 2014;76:191-5.

18 Mitchell F, Gilmour M, McLaren G. Hospital discharge: a descriptive study of the patient journey for frail older people with complex needs. J Integr Care 2010;18:30-6.

19 Tan WS, Chong WF, Chua KSG, et al. Factors associated with delayed discharges after inpatient stroke rehabilitation in Singapore. Ann Acad Med Singap 2010;39:435-41.
20 Landeiro F, Leal J, Gray AM. The impact of social isolation on delayed Hospital discharges of older hip fracture patients and associated costs. Osteoporos Int 2016;27:737-45.

21 Poulos CJ, Magee C, Bashford G, et al. Determining level of care appropriateness in the patient journey from acute care to rehabilitation. BMC Health Serv Res 2011;11:291-91.

22 Zeitz KM, Carter L, Robinson C. The ebbs and flows of changing acute bed capacity delays. Aust Health Rev 2013;37:66-9.

23 Anderson ME, Glasheen JJ, Anoff D, et al. Understanding predictors of prolonged hospitalizations among general medicine patients: a guide and preliminary analysis. J Hosp Med 2015;10:623-6.

24 Hendy P, Patel JH, Kordbacheh T, et al. In-depth analysis of delays to patient discharge: a metropolitan teaching hospital experience. Clin Med 2012;12:320-3.

25 Salonga-Reyes A, Scott IA. Stranded: causes and effects of discharge delays involving non-acute in-patients requiring maintenance care in a tertiary hospital general medicine service. Aust Health Review 2017;41:54-62.

26 Sutherland JM, Repin N, Crump RT. Paying for hospital services: a hard look at the options. Toronto, Canada: CD Howe Institute, 2013: 1-32.

27 Sutherland J. Hospital payment policy in Canada: options for the future. Canadian Health Services Research Foundation, 2011.

28 Ontario Ministry of Health and Long-Term Care. Quality-based procedures indicators: an implementation guidance document. Ontario, Canada, 2014: 1-38.

29 David G, Polsky D. Economics of Home Health Services. In: Culyer AJ, ed. Encyclopedia of health economics. San Diego: Elsevier, 2014: 477-83.

30 Treasury HM. Spring budget 2017. United Kingdom, 2017.

31 Knowles G, Burke MR, Carr M. Independent expert review of delayed discharges: Department of health, 2018.

32 Fagan L. 'Bed blockers' costing Ottawa hospitals millions. Glut of patients awaiting more appropriate care a 'crisis, ' health workers say. Ottawa: CBC News, 2019.

33 McCloskey R, Jarrett P, Stewart C. The untold story of being designated an alternate level of care patient. Healthc Policy 2015;11:76-89.

34 Munn Z, Peters MDJ, Stern C, et al. Systematic review or scoping review? Guidance for authors when choosing between a systematic or scoping review approach. BMC Med Res Methodol 2018; $18: 143$.

35 Levac D, Colquhoun H, O'Brien KK. Scoping studies: advancing the methodology. Implement Sci 2010;5:69.

36 Tricco AC, Lillie E, Zarin W, et al. PRISMA extension for scoping reviews (PRISMA-ScR): checklist and explanation. Ann Intern Med 2018:169:467-73.

37 Bramer WM, Giustini D, de Jonge GB, et al. De-duplication of database search results for systematic reviews in endnote. $J$ Med Libr Assoc 2016;104:240-3.

38 Babineau J. Product review: Covidence (systematic review software). J Can Health Libr Assoc 2014;35:68-71.

39 Doern GB, Phidd RW. Canadian public policy: ideas, stucture and process. 2nd. Toronto, Canada: Nelson Canada, 1992.

40 Adlington K, Brown J, Ralph L, et al. Better care: reducing length of stay and bed occupancy on an older adult psychiatric ward. BMJ Open Qual 2018:7:e000149.

41 Boyd SS. Hospital administrators' strategies for reducing delayed Hospital discharges and improving profitability. Walden Dissertations and Doctoral Studies 2017:1.

42 Caminiti C, Meschi T, Braglia L, et al. Reducing unnecessary Hospital days to improve quality of care through physician accountability: a cluster randomised trial. BMC Health Serv Res 2013;13:14.

43 Patel H, Yirdaw E, Yu A, et al. Improving early discharge using a team-based structure for discharge multidisciplinary rounds. Prof Case Manag 2019;24:83-9.

44 Ali Pirani SS. Prevention of delay in the patient discharge process: an emphasis on nurses' role. J Nurses Staff Dev 2010;26:E1-5.

45 Sutherland J, Crump R. Alternative Level of Care: Canada's Hospital Beds, the Evidence and Options. Hcpol 2013;9:26-34.

46 Anonymous. Patient flow initiatives decrease LOS, up capacity. Hosp Case Manag 2010;18:117-24.

47 Brankline AL, Coyle CM, Jencks KA, et al. Practical innovations: technology-assisted referrals. Soc Work Health Care 2009;48:768-76.

48 Henwood M. Effective partnership working: a case study of hospital discharge. Health Soc Care Community 2006;14:400-7.

49 Maloney CG, Wolfe D, Gesteland PH, et al. A tool for improving patient discharge process and hospital communication practices: the "Patient Tracker". AMIA Annu Symp Proc 2007:493-7. 
50 Roberts K, Stiller K, Harling R, et al. Impacts and perceptions of a computer-based length of stay benchmarking program. Int $J$ Ther Rehabil 2013;20:237-45.

51 Sobotka SA, Agrawal RK, Msall ME. Prolonged hospital discharge for children with technology dependency: a source of health care disparities. Pediatr Ann 2017;46:e365-70.

52 Williams TA, Leslie GD, Brearley L, et al. Discharge delay, room for improvement? Aust Crit Care 2010;23:141-9.

53 Younis J, Salerno G, Fanto D, et al. Focused preoperative patient stoma education, prior to ileostomy formation after anterior resection, contributes to a reduction in delayed discharge within the enhanced recovery programme. Int $J$ Colorectal Dis 2012;27:1-5.

54 Chidwick P, Oliver J, Ball D, et al. Six change ideas that significantly minimize alternate level of care (alc) days in acute care hospitals. Healthc Q 2017;20:37-43.

55 Baumann M, Evans S, Perkins M, et al. Organisation and features of hospital, intermediate care and social services in English sites with low rates of delayed discharge. Health Soc Care Community 2007;15:295-305.

56 Burr E, Dickau S. Leading practices in alternate levels of care (alc) avoidance: a standardized approach. Hcq 2017;20:44-7.

57 Holland DE, Pacyna JE, Gillard KL. Tracking discharge delays: critical first step toward mitigating process Breakdowns and Inefficiencies. J Nurs Care Qual 2016;31:17-23.

58 Lian YC, Ying SHK, Peng CC, et al. Early discharge study for premature infants: Singapore General Hospital. Perm J 2008;12:15-18.

59 Mahant S, Peterson R, Campbell M, et al. Reducing inappropriate hospital use on a general pediatric inpatient unit. Pediatrics 2008;121:e1068-73.

60 Moeller JJ, Ma M, Hernandez P, et al. Discharge delay in patients with community-acquired pneumonia managed on a critical pathway. Can J Infect Dis Med Microbiol 2006;17:109-13.

61 Mur-Veeman I, Govers M. Buffer management to solve bedblocking in the Netherlands 2000-2010. Cooperation from an integrated care chain perspective as a key success factor for managing patient flows. Int J Integr Care 2011;11:e080.

62 Niemeijer GC, Trip A, Ahaus KTB, et al. Quality in trauma care: improving the discharge procedure of patients by means of lean six sigma. J Trauma 2010;69:614-9.

63 Ardagh MW, Tonkin G, Possenniskie C. Improving acute patient flow and resolving emergency department overcrowding in New Zealand hospitals--the major challenges and the promising initiatives. $N Z$ Med J 2011;124:64-73.

64 Brown I, Jellish WS, Kleinman B, et al. Use of postanesthesia discharge criteria to reduce discharge delays for inpatients in the postanesthesia care unit. J Clin Anesth 2008;20:175-9.

65 Gutmanis I, Speziale J, Bussel L, et al. The South West local health integration network behavioural supports Ontario experience. Hcq 2016;18:50-6.

66 Lees-Deutsch L, Jackson J, Balaji A, et al. Developing a process for Criteria-Led discharge: selection of patients for efficient and effective discharge (speed). J Nurs Care Qual 2020;35:35:140-6.

67 Toronto Central Community Care Access Centre. ALC avoidance leading practices and improvement strategies for the acute care sector. Ontario, Canada, 2015.

68 Arendts G, Fitzhardinge S, Pronk K, et al. Front-loading allied health intervention in the emergency department does not reduce length of stay for admitted older patients. Int J Clin Pract 2013;67:807-10.

69 Béland F, Bergman H, Lebel P, et al. A system of integrated care for older persons with disabilities in Canada: results from a randomized controlled trial. J Gerontol A-Biol 2006;61:367-73.

70 Blecker S, Goldfeld K, Park H, et al. Impact of an intervention to improve weekend hospital care at an academic medical center: an observational study. J Gen Intern Med 2015;30:1657-64.

71 Boutette M, Hoffer A, Plant J, et al. Establishing an integrated model of subacute care for the frail elderly. Healthc Manage Forum 2018;31:133-6.

72 Bowen A, Kumar R, Howard J, et al. Nurse led discharge: improving efficiency, safely. Clin Govern Int J 2014;19:110-6.

73 El-Eid GR, Kaddoum R, Tamim H, et al. Improving hospita discharge time: a successful implementation of six sigma methodology. Medicine 2015;94:e633.

74 Graham L, Neal CP, Garcea G, et al. Evaluation of nurse-led discharge following laparoscopic surgery. J Eval Clin Pract 2012;18:19-24.

75 Maessen JMC, Dejong CHC, Kessels AGH, et al. Length of stay: an inappropriate readout of the success of enhanced recovery programs. World J Surg 2008;32:971-5.
76 Mahto R, Venugopal H, Vibhuti VS, et al. The effectiveness of a hospital diabetes outreach service in supporting care for acutely admitted patients with diabetes. QJM 2009;102:203-7.

77 Meehan L, Banarsee R, Dunn-Toroosian V, et al. Improving outcomes for patients discharged early using a home assessment scheme. London J Prim Care 2018;10:62-7.

78 Panis LJGG, Verheggen FWSM, Pop P, et al. The impact of hospital discharge on inappropriate hospital stay. Int J Health Care Qual Assur Inc Leadersh Health Serv 2004;17:189-93.

79 Sampson MJ, Crowle T, Dhatariya K, et al. Trends in bed occupancy for inpatients with diabetes before and after the introduction of a diabetes inpatient specialist nurse service. Diabet Med 2006;23:1008-15

80 Starr-Hemburrow L, Parks JM, Bisaillon S. Home first: reducing ALC and achieving better outcomes for seniors through interorganizational collaboration. Healthc Q 2011;14:70-6.

81 Taber DJ, Pilch NA, McGillicuddy JW, et al. Improved patient safety and outcomes with a comprehensive interdisciplinary improvement initiative in kidney transplant recipients. Am J Med Qual 2013;28:103-12.

82 Udayai K, Kumar P. Implementing six sigma to improve hospital discharge process. Int J Pharm Sci Res 2012;3:4528-32.

83 Calveley P. Doing, not talking: hospital admission avoidance. Nursing and Residential Care 2007;9:230-2.

84 Central East LHIN ALC Task Group. Alternate level of care systems issues and recommendations. Ontario, Canada, 2008.

85 Joint Improvement Team. Home First - Ten Actions to Transform Discharge. United Kingdom, 2013.

86 Krystal A. Southlake at home Webinar. Canada, 2019.

87 LHIN Collaborative. Sharing Best Practices: Transition Management in Ontario - Home First: Implementation Guide and Toolkit. Ontario, Canada, 2011.

88 North West Community Care Access Centre. Wait at home fact sheet. Ontario, Canada, 2011.

89 Shah N. A new philosophy towards solving the alc crisis (home first. Ontario, Canada, 2010.

90 Shah N. A call to action on ER/ALC: promoting effective care across the health continuum. Ontario, Canada, 2011.

91 Starr-Hemburrow L. Home First - Optimizing Patient Flow and Patient Centred Care Canada, 2010.

92 Province of New Brunswick. Health annual report 2016-2017. New Brunswick, Canada, 2017.

93 Behan D. Delayed transfers of care - an early review of progress. $J$ Integr Care 2005;13:43-8.

94 Levin KA, Crighton E. Measuring the impact of step down intermediate care on delayed discharge: an interrupted time series analysis. J Epidemiol Community Health 2019;73:674-9.

95 Manville M, Klein MC, Bainbridge L. Improved outcomes for elderly patients who received care on a transitional care unit. Can Fam Physician 2014;60:e263-71.

96 Rae B, Busby W, Millard PH. Fast-tracking acute hospital care from bed crisis to bed crisis. Aust. Health Review 2007;31:50-62.

97 Shah A. The impact of the community care (delayed discharge) act 2003 on the length of stay and bed occupancy in old age psychiatry units in England. Int J Geriatr Psychiatry 2007;22:1164-5.

98 Adams S. Care \& Repair England. Reducing Delayed Transfer of Care through housing interventions: Evidence of Impact. United Kingdom, 2017

99 Expedited discharge fund helps uninsured patients. Plan frees up beds for patients who can pay. Hosp Case Manag 2008;16:70-5.

100 Manzano-Santaella A. Payment by results and delayed discharges. Bri J Healthcare Manag 2009;15:440-3.

101 Gaughan J, Gravelle H, Siciliani L. Testing the bed-blocking hypothesis: does nursing and care home supply reduce delayed Hospital discharges? Health Econ 2015;24(Suppl 1):32-44.

102 Katsaliaki K, Brailsford S, Browning D, et al. Mapping care pathways for the elderly. J Health Organ Manag 2005;19:57-72.

103 Qin S, Thompson C, Bogomolov T, et al. Hospital occupancy and discharge strategies: a simulation-based study. Intern Med J 2017:47:894-9.

104 NHS Improvement. Guide to reducing long Hospital stays. United Kingdom, 2018.

105 Hamilton AB, Finley EP. Qualitative methods in implementation research: an introduction. Psychiatry Res 2019;280:112516.

106 Southam-Gerow MA, Dorsey S. Qualitative and mixed methods research in dissemination and implementation science: introduction to the special issue. J Clin Child Adolesc Psychol 2014;43:845-50.

107 Qualitative Research in Implementation Science group. Qualitative methods in implementation science. United States: National Cancer Institute, Division of Cancer Control and Population Sciences, 2019: 1-31. 
108 Shelton RC, Cooper BR, Stirman SW. The sustainability of evidence-based interventions and practices in public health and health care. Annu Rev Public Health 2018;39:55-76.

109 Geerligs L, Rankin NM, Shepherd HL, et al. Hospital-based interventions: a systematic review of staff-reported barriers and facilitators to implementation processes. Implementation Sci 2018;13:36.

110 Green LW, Glasgow RE. Evaluating the relevance, generalization, and applicability of research: issues in external validation and translation methodology. Eval Health Prof 2006;29:126-53.
111 Balasubramanian BA, Cohen DJ, Davis MM, et al. Learning evaluation: blending quality improvement and implementation research methods to study healthcare innovations. Implementation Sci 2015;10:31.

112 Glasby J, Littlechild R, Pryce K. Show me the way to go home: a narrative review of the literature on delayed Hospital discharges and older people. Br J Soc Work 2004;34:1189-97.

113 Zhao G, Kennedy C, Mabaya G, et al. Patient engagement in the development of best practices for transitions from hospital to home: a scoping review. BMJ Open 2019;9:e029693. 